\title{
2-arachidonoylglycerol reduces chondroitin sulphate proteoglycan production by astrocytes and enhances oligodendrocyte differentiation under inhibitory conditions
}

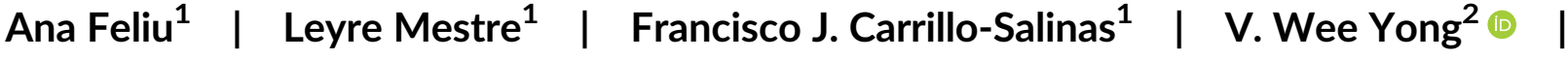 \\ Miriam Mecha $^{1}$ | Carmen Guaza ${ }^{1}$ (i)
}

${ }^{1}$ Functional and Systems Neurobiology Department, Neuroimmunology Group, Instituto Cajal, CSIC, Madrid, Spain

${ }^{2}$ Hotchkiss Brain Institute and the Department of Clinical Neurosciences and Oncology, University of Calgary, Calgary, Alberta, Canada

\section{Correspondence}

Miriam Mecha Rodríguez and Carmen Guaza, Instituto Cajal, CSIC, Av. Doctor Arce

37, 28002 Madrid, Spain.

Email: miriammecha@cajal.csic.es (M. M. R.) and

Email: cgjb@cajal.csic.es (C. G)

Present address

Francisco J. Carrillo-Salinas, Department of Immunology, Tufts University School of Medicine, Boston, MA.

Funding information

Ministry of the Economy and Competition, Grant/Award Numbers: SAF2013-42784-R, SAF2016-76449-R; Red Española de Esclerosis Múltiple, Grant/Award Number:

RD16/0015/0021; Ministerio de Economía y Competitividad, Grant/Award Number: BES2014-068459

\begin{abstract}
The failure to remyelinate and regenerate is a critical impediment to recovery in multiple sclerosis (MS), resulting in severe dysfunction and disability. The chondroitin sulfate proteoglycans (CSPGs) that accumulate in MS lesions are thought to be linked to the failure to regenerate, impeding oligodendrocyte precursor cell (OPC) differentiation and neuronal growth. The potential of endocannabinoids to influence MS progression may reflect their capacity to enhance repair processes. Here, we investigated how 2-arachidonoylglycerol (2-AG) may affect the production of the CSPGs neurocan and brevican by astrocytes in culture. In addition, we studied whether 2-AG promotes oligodendrocyte differentiation under inhibitory conditions in vitro. Following treatment with 2-AG or by enhancing its endogenous tone through the use of inhibitors of its hydrolytic enzymes, CSPG production by rat and human TGF- $\beta 1$ stimulated astrocytes was reduced. These effects of 2-AG might reflect its influence on TGF- $\beta 1 /$ SMAD pathway, signaling that is involved in CSPG upregulation. The matrix generated from 2-AG-treated astrocytes is less inhibitory to oligodendrocyte differentiation and significantly, 2-AG administration directly promotes the differentiation of rat and human oligodendrocytes cultured under inhibitory conditions. Overall, the data obtained favor targeting the endocannabinoid system to neutralize CSPG accumulation and to enhance oligodendrocyte differentiation.
\end{abstract}

\section{KEYWORDS}

2-AG, multiple sclerosis, astrocytes, CSPGs, oligodendrocytes

\section{1 | INTRODUCTION}

Multiple sclerosis (MS) is a neurodegenerative disease in which inflammation, demyelination, axonal damage, and gliosis affect the central nervous system (CNS), leading to progressive neurological decline and permanent disability (Compston \& Coles, 2008; Lassmann, 2017; Lassmann, Bruck, \& Lucchinetti, 2001). Repair in MS takes place spontaneously in the form of remyelination, yet as the disease progresses remyelination fails (Chang et al., 2012; Chang, Tourtellotte,
Rudick, \& Trapp, 2002; Franklin, 2002; Goldschmidt, Antel, Konig, Bruck, \& Kuhlmann, 2009). It appears that this failure of remyelination is not generally due to a loss of oligodendrocytes at the demyelinated MS lesions, the CNS cells that produce myelin (Chang et al., 2002, 2012), but rather, to an impediment in the successful remyelination of damaged axons (Franklin, 2002). Hence, remyelination may be inhibited by factors in the lesion's extracellular milieu and astrogliosis. Astrocytes become reactive in MS lesions, facilitating blood-brain barrier (BBB) repair, secreting immunosuppressive molecules and 
exerting neuroprotective properties. However, astrocytes can also exacerbate the insult by secreting pro-inflammatory molecules and they are essential for glial scar formation at demyelinated lesions (Frischer et al., 2015), sites where there is an increase in the synthesis and accumulation of chondroitin sulfate proteoglycans (CSPGs) (Back et al., 2005; Chang et al., 2012; Sobel \& Ahmed, 2001).

A basal level of CSPG production is necessary to maintain the extracellular matrix (ECM) in a state that favors synaptic stabilization and plasticity (Carulli et al., 2006; Galtrey \& Fawcett, 2007). Following injury, CSPGs are immediately upregulated to limit tissue damage (Silver \& Miller, 2004), yet when CSPG accumulation persists, spontaneous repair mechanisms are inhibited due to the formation of a nonpermissive environment that restricts oligodendrocyte precursor cell (OPC) differentiation (Chang et al., 2012; Karus et al., 2016; Lau et al., 2012; Pendleton et al., 2013; Siebert \& Osterhout, 2011; Sobel \& Ahmed, 2001). Importantly, CSPG clearance through the digestion of their glycosaminoglycan (GAG) chains, or the blockage of CSPG synthesis and the disruption of CSPG receptors, all provoke remyelination and axon regeneration in culture, as well as in different experimental conditions of demyelination and spinal cord injury (SCI) (Bartus et al., 2014; Dyck et al., 2015; Dyck, Kataria, Akbari-Kelachayeh, Silver, \& Karimi-Abdolrezaee, 2019; Keough et al., 2016; Lang et al., 2015; Lau et al., 2012; Rolls et al., 2008; Siebert \& Osterhout, 2011).

Cannabinoid based therapies are of particular interest in MS, but also in other pathological scenarios like adenoleukodystrophies, $\mathrm{SCl}$ and a variety of neurodegenerative diseases that require reparative/ remyelination therapeutic approaches. In animal models of MS, cannabinoids have been found to display the potential to relieve symptoms and to control inflammation, neurodegeneration, and demyelination. In general, exogenous and endogenous cannabinoids can behave as agents with multiple targets acting as an antioxidant (phytocannabinoids), anti-excitotoxic and neuroprotective lipids (Fernández-Ruiz, García, Sagredo, Gómez-Ruiz, \& de Lago, 2010; Loría et al., 2010; Mecha et al., 2015; Pryce et al., 2003). Indeed, cannabinoid signaling may enhance the activity of reparative mechanisms, as they can protect OPCs from inflammatory and excitotoxic damage (Bernal-Chico et al., 2015; Gómez et al., 2010; Mecha et al., 2012; Molina-Holgado et al., 2002). In particular, the endocannabinoid 2-arachidonoylglycerol (2-AG) promotes the proliferation and differentiation of OPCs (Gómez et al., 2010, 2011, 2015) and it regulates their migration in culture (Sánchez-Rodríguez, Gómez, Esteban, García-Ovejero, \& Molina-Holgado, 2018). Actually, in vivo studies also demonstrated that inhibiting 2-AG catabolism through the inhibition of monoacylglycerol lipase (MAGL) or the direct administration of 2-AG attenuates symptomatology and promotes remyelination in the autoimmune EAE model (Bernal-Chico et al., 2015; Hernández-Torres et al., 2014; Lourbopoulos et al., 2011), as well as in the Theiler virus model of MS (Feliu et al., 2017; Mecha et al., 2019). The effects of 2-AG on disease activity and remyelination in the latter progressive model of MS are dependent on the CB1 and CB2 cannabinoid receptors (CB1R and $C B 2 R$ ), and they involve immune modulation in conjunction with a reduction in astrogliosis and CSPG deposition (Feliu et al., 2017).
In the present study, we reveal an effect of 2-AG and the inhibition of its hydrolytic enzymes on the production of the CSPGs neurocan and brevican by astrocytes in culture. In addition, we assessed whether 2-AG promotes oligodendrocyte differentiation under inhibitory conditions in order to evaluate the potential of the endocannabinoid system to enhance the endogenous repair mechanisms that are dampened in conditions of chronic demyelination.

\section{2 | MATERIALS AND METHODS}

\subsection{Rat astrocyte cell cultures}

Rat astrocytes were prepared from postnatal Wistar pups (0-2 days old) as described previously (Mecha et al., 2011). After isolation, the astrocytes were plated in Poly-D-lysine (\#P7280; $5 \mu \mathrm{g} / \mathrm{ml}$, SigmaAldrich, Madrid, Spain) coated 6-well plates at a density of $1 \times 10^{6}$ cells/ml for western blot and RT-PCR analysis, or on coverslips in 24-well plates at a density of $3 \times 10^{5}$ cells $/ \mathrm{ml}$ for immunocytochemistry and they were grown at $37^{\circ} \mathrm{C}$ in an atmosphere of $5 \% \mathrm{CO}_{2}$ and in DMEM medium (Lonza Ibérica S.A., Barcelona, Spain) supplemented with $5 \%$ horse serum, $5 \%$ fetal bovine serum (FBS; Vector Laboratories $\mathrm{Inc}$, Burlingame, CA), $100 \mathrm{U} / \mathrm{ml}$ penicillin and $100 \mathrm{mg} / \mathrm{ml}$ streptomycin (Gibco-Invitrogen S.A., Barcelona, Spain). This medium was replaced $3 \mathrm{hr}$ later, supplemented with cytosine-d-arabinofuranoside (\#C1768, AraC $10 \mu \mathrm{M}$ : Sigma-Aldrich Madrid, Spain). After 3 days in vitro, the cells were incubated for $1 \mathrm{hr}$ in serum-free DMEM prior to the 1, 6, and $24 \mathrm{hr}$ pharmacological treatments. The cells harvested at $6 \mathrm{hr}$ were processed for RT-PCR, the ones harvested at $24 \mathrm{hr}$ were processed also for RT-PCR, immunocytochemistry, and CSPGs were analyzed in western blots, whereas the cells harvested at $1 \mathrm{hr}$ were used to study signaling pathways. Supernatants from the cells incubated with the stimuli for $24 \mathrm{hr}$ were analyzed by ELISA.

\section{2 | Rat astrocyte-secreted ECM}

To generate an anchored astrocyte ECM, astrocytes were seeded on coverslips in 24-well plates at a density of $3 \times 10^{5} \mathrm{cells} / \mathrm{ml}$ in DMEM medium supplemented with $5 \%$ horse serum, $5 \%$ FBS, $100 \mathrm{U} / \mathrm{ml}$ penicillin and $100 \mathrm{mg} / \mathrm{ml}$ streptomycin. The medium was replaced $3 \mathrm{hr}$ later, adding $\operatorname{AraC}(10 \mu \mathrm{M})$. After 3 days in vitro, the cells were incubated for $1 \mathrm{hr}$ in serum-free DMEM prior to treatment for $24 \mathrm{hr}$ with human TGF- $\beta 1$ (20 ng/ml: Peprotech, London, UK) and the endocannabinoid 2-AG (100 nM: Tocris Bioscience, Bristol, UK). The cells were then rinsed with PBS, and treated with Versene (\#15040066; $0.2 \mathrm{~g} / \mathrm{ml}$ EDTA, Gibco-Invitrogen S.A., Barcelona, Spain) for $30 \mathrm{~min}$ at $37^{\circ} \mathrm{C}$ and in $5 \% \mathrm{CO}_{2}$, and dislodging the cells with a $200 \mathrm{ml}$ micropipette. The cell debris was removed by rinsing with PBS and the absence of cells was confirmed by phase-contrast microscopy. The ECM deposited on the 24-well plate was kept hydrated with PBS (Gibco-Invitrogen S.A., Barcelona, Spain) at $4^{\circ} \mathrm{C}$ until OPCs were seeded. 


\section{3 | Rat oligodendrocyte cultures}

Oligodendrocyte cultures derived from P0-P2 Wistar rats were prepared as described previously (Mecha et al., 2011). The cells isolated were plated on coverslips coated with Poly-D-lysine $(5 \mu \mathrm{g} / \mathrm{ml})$ or a CSPG mixture (\#CC117, $1 \mu \mathrm{g} / \mathrm{ml}$ containing a mixture of aggrecan, neurocan, phosphacan, and versican: Millipore, Temecula, CA) in 24-well plates at a density of $4 \times 10^{5}$ cells $/ \mathrm{ml}$ for immunocytochemistry. The cells were maintained for $24 \mathrm{hr}$ at $37^{\circ} \mathrm{C}$ and $5 \% \mathrm{CO}_{2}$ in Oligodendrocyte medium: serum-free DMEM containing B27, BSA (0.1 mg/ml: Gibco-Invitrogen, Barcelona, Spain), progesterone (\#P6149; $6 \mathrm{ng} / \mathrm{ml}$ : Sigma-Aldrich, Madrid, Spain), putrescine (\#P7505; $1 \mu \mathrm{g} / \mathrm{ml}$ : Sigma-Aldrich, Madrid, Spain), sodium selenite (\#S9133; $5 \mathrm{ng} / \mathrm{ml}$ : Sigma-Aldrich, Madrid, Spain), T3 (\#T5516; 40 ng/ml: Sigma-Aldrich, Madrid, Spain), Glutamax (\#35050061; 2 mM: Gibco-Invitrogen, Barcelona, Spain), insulin (\#I1882; $5 \mu \mathrm{g} / \mathrm{ml}$ : Sigma-Aldrich, Madrid, Spain), apotransferrin (\#T1147; 25 g/ml: Sigma-Aldrich, Madrid, Spain), biotin (\#B4639; $2.44 \mu \mathrm{g} / \mathrm{ml}$ : Sigma-Aldrich, Madrid, Spain), hydrocortisone (\#H2270; 10 ng/ml: Sigma-Aldrich, Madrid, Spain), penicillin/streptomycin (\#15070063; 1\%: Gibco-Invitrogen, Barcelona, Spain), and sodium pyruvate (\#11360070; 1 mM: Gibco-Invitrogen, Barcelona, Spain). In another set of experiments, isolated oligodendrocytes were plated for $24 \mathrm{hr}$ in the same media on a rat astrocyte-derived matrix.

\section{4 | Human astrocyte cultures}

Brain tissue from 18- to 20-week-old therapeutically aborted fetuses were used in accordance with the ethics approval from the Research Ethics Board at the University of Calgary. Astrocytes were purified by dissociating the tissue into single cells, as described previously (Giuliani, Goodyer, Antel, \& Yong, 2003). Briefly, 5-15 g of brain tissue was cut into $1 \mathrm{~mm}$ fragments with a pair of scalpels and incubated for $15 \mathrm{~min}$ at $37^{\circ} \mathrm{C}$ in $40 \mathrm{ml} \mathrm{PBS}$ containing $0.25 \%$ trypsin (Gibco-Invitrogen) and $200 \mathrm{~g} / \mathrm{ml}$ DNase I (Roche Boehringer). The suspension was then washed through a $130 \mu \mathrm{m}$ pore size filter, and the flowthrough was centrifuged at $1200 \mathrm{rpm}$ for $10 \mathrm{~min}$. The cell pellet was resuspended in PBS, centrifuged again and plated in T-75 flasks coated with $10 \mu \mathrm{g} / \mathrm{ml}$ poly-L-ornithine at a density of $2 \times 10^{6}$ cells $/ \mathrm{ml}$ in feeding medium (MEM-supplemented with 10\% FBS [Gibco-Invitrogen], $0.1 \%$ dextrose [Sigma-Aldrich], $1 \mathrm{mM}$ sodium pyruvate [Gibco-Invitrogen], and $1 \%$ penicillin/streptomycin, [Gibco-Invitrogen]). The cultures were passaged seven to eight times over 4-5 weeks, depleting the neurons and achieving 95\% astrocyte purity. The flasks were washed with PBS and trypsinized to obtain the astrocytes, which were then plated in poly-L-ornithine $(10 \mu \mathrm{g} / \mathrm{ml})$ (SigmaAldrich) coated 6-well plates at a density of $1 \times 10^{6} \mathrm{cells} / \mathrm{ml}$, and they were grown in feeding medium at $37^{\circ} \mathrm{C}$ and in an atmosphere of $5 \%$ $\mathrm{CO}_{2}$. The medium was replaced $3 \mathrm{hr}$ later, adding AraC $(10 \mu \mathrm{M}$ : Sigma-Aldrich), and after 3 days in vitro, the cells were incubated for $1 \mathrm{hr}$ in serum-free DMEM prior to their pharmacological treatment for $24 \mathrm{hr}$. The CSPGs in the cells harvested were analyzed in western blots and the supernatants were used for ELISA studies.

\section{5 | Isolation of human oligodendrocytes}

Human adult oligodendrocytes were cultured from resected brain specimens obtained from patients undergoing surgery to treat intractable epilepsy and they were cultured as described previously (Nuttall et al., 2007). The tissues used were adjacent to the epileptic foci in cortical areas and this material was used in accordance with the ethics approval obtained from the Research Ethics Board at the University of Calgary. In brief, the pieces of the brain targeted for excision were suctioned into a sterile bag using a Cavitron Ultrasonic Aspirator. Tissue fragments less than $2 \mathrm{~mm}^{3}$ were immersed in saline in the sterile bag at room temperature $\left(23^{\circ} \mathrm{C}\right)$, which was transported to the tissue culture laboratory for processing within the hour of completing the surgery at room temperature. The content of the sterile bag was put into $50 \mathrm{ml}$ tubes at room temperature, and the blood, meninges, and clots were removed by washing the tissue several times with PBS, allowing the contents of the brain to settle between washes. The tissue was transferred to a sterile $100 \mathrm{ml}$ glass bottle for digestion with DNase I $(0.1 \mathrm{mg} / \mathrm{ml}$, Roche Boehringer) and $0.25 \%$ trypsin in PBS, and it was incubated at $37^{\circ} \mathrm{C}$ for $25 \mathrm{~min}$. FBS was added to inactivate the trypsin and the sample was filtered through sterile $130 \mu \mathrm{m}$ mesh. After centrifugation at $1200 \mathrm{rpm}$ for $10 \mathrm{~min}$, the sample was diluted in $21 \mathrm{ml}$ of PBS and laid over $9 \mathrm{ml}$ of Percoll (GE Healthcare Bio-Sciences $A B$ ) in sterile 6-8 polycarbonate ultra-centrifuge tubes. The sample was homogenized using a pipette and the cells recovered by centrifugation in a Beckman $\mathrm{J} 2-21 \mathrm{M}$ centrifuge at $15,000 \mathrm{rpm}$ for $30 \mathrm{~min}$ at $4^{\circ} \mathrm{C}$ with no brakes. After Percoll gradient centrifugation, the myelin was removed by aspiration from the upper layer, and the viable cell layer was pipetted and diluted 1:1 in PBS. The cells were washed twice for $10 \mathrm{~min}$ by centrifugation at $1200 \mathrm{rpm}$ in MEM containing $0.2 \mathrm{mM}$ Glutamine, $100 \mu \mathrm{g} / \mathrm{ml}$ penicillin/streptomycin, $1 \times$ nonessential amino acids, $1 \times$ sodium pyruvate, $0.1 \%$ dextrose and $10 \%$ inactivated FBS (all from Gibco-Invitrogen). Finally, the cells were suspended in medium, plated at $2 \times 10^{6}$ cells $/ \mathrm{ml}$ in $5 \mathrm{~mL}$ uncoated T25 Flask and incubated for $48 \mathrm{hr}$ at $37^{\circ} \mathrm{C}$ in an atmosphere of $5 \%$ $\mathrm{CO}_{2}$. Microglia strongly adhere to the flask while oligodendrocytes remained in suspension or were loosely attached. Neurons do not survive the isolation procedure while astrocytes are lost in the discarded Percoll fractions. The floating oligodendrocytes were collected, centrifuged and plated onto poly-L-ornithine $(10 \mu \mathrm{g} / \mathrm{ml})$ or on a CSPG mixture (\#CC117, $1 \mu \mathrm{g} / \mathrm{ml}$, Sigma-Aldrich) in 96-well coated plates at a density of $10^{5}$ cells/well in human oligodendrocyte medium: DMEM/F12 (Gibco-Invitrogen) medium containing N2 supplement, Glutamax (2 mM, Gibco-Invitrogen), sodium pyruvate (1 mM, Gibco-Invitrogen), penicillin/streptomycin (1\%, Gibco-Invitrogen), insulin (5 $\mu \mathrm{g} / \mathrm{ml}$, Gibco-Invitrogen), holo-transferrin (50 $\mu \mathrm{g} / \mathrm{ml}$ : Sigma-Aldrich), N-acetylcysteine ( $5 \mu \mathrm{g} / \mathrm{ml}$ : Sigma-Aldrich), biotin $(0.01 \mu \mathrm{g} / \mathrm{ml}$ : Sigma-Aldrich), Trace Elements $B$, dextrose ( $1 \mathrm{mg} / \mathrm{ml}$ : Sigma-Aldrich), BSA (0.1 mg/ml: Sigma-Aldrich), progesterone $(60 \mathrm{ng} / \mathrm{ml}$, Sigma-Aldrich), putrescine $(16 \mu \mathrm{g} / \mathrm{ml}$, SigmaAldrich), Sodium Selenite (30 nM: Gibco-Invitrogen), and T3 (30 nM: Sigma-Aldrich). 


\section{6 | Oligodendrocyte differentiation on a purified CSPG mixture}

To determine the effects of CSPGs on oligodendrocyte growth in vitro, 96-well plates for human oligodendrocytes and 24-well plates for rat oligodendrocytes were first coated with $10 \mu \mathrm{g} / \mathrm{ml}$ poly-L-lysine overnight and then rinsed with water. The plates were coated for 3-4 hr with purified CSPGs (\#CC117) at a concentration of $1 \mu \mathrm{g} / \mathrm{ml}$ diluted in sterile water, then rinsed in water. The control wells contained poly-L-lysine alone. Enriched OPCs were seeded as described previously and the plates were incubated for $24 \mathrm{hr}$. The cells were fixed with $4 \%$ ice-cold paraformaldehyde at $4^{\circ} \mathrm{C}$ for $20 \mathrm{~min}$, rinsed with PBS, and stored at $4^{\circ} \mathrm{C}$ until they were processed for immunocytochemistry. In other experiments, rat OPCs were seeded onto rat astrocyte secreted ECM.

\subsection{Reagents and treatments}

Rat astrocytes were exposed to the cytokine human TGF- $\beta 1$ (\#10021C, $20 \mathrm{ng} / \mathrm{ml}$ : Peprotech, London, UK), bFGF (10 ng/ml: Peprotech, London, UK), the endocannabinoid 2-AG (\#1298/10, at 10, 50, $100 \mathrm{nM}$ and $500 \mathrm{nM}$ : Tocris, Bioscience, Bristol, UK), and the CB1R (SR141716A, $1 \mu \mathrm{M}$ : Sanofi Recherche, Montpellier, France) and CB2R (\#1120/10, AM630, $1 \mu \mathrm{M}$ or \#5039/10, SR144528 [SR2], $1 \mu \mathrm{M}$, both from Tocris Bioscience, Bristol, UK) antagonists for $24 \mathrm{hr}$, administered $30 \mathrm{~min}$ before 2-AG treatment. In another subset of experiments, astrocytes were treated for $24 \mathrm{hr}$ with inhibitors of the 2-AG hydrolytic enzymes, the MAGL inhibitors UCM03025 (1 $\mu \mathrm{M}$ : Department of Organic Chemistry, Universidad Complutense de Madrid) and JZL184 (\#3836/10, $1 \mu \mathrm{M}$ : Tocris, Bioscience, Bristol, UK), and an inhibitor of the ABHD6 hydrolase enzyme, WWL70 (\#3252/10, $10 \mu \mathrm{M}$ : Tocris, Bioscience, Bristol, UK). To study cell signaling, TGF- $\beta 1,2-A G$, and cannabinoid receptor antagonists were administered for $1 \mathrm{hr}$, as well as the inhibitor of the TGF $\beta$-SMAD pathway, SB431542 (\# S4317, $20 \mu$ M, Sigma-Aldrich, Madrid, Spain). Primary human astrocytes were treated for $24 \mathrm{hr}$ with TGF- $\beta 1$ $(10 \mathrm{ng} / \mathrm{ml})$ and $2-\mathrm{AG}$ at 10,50 , and $100 \mathrm{nM}$. Primary rat oligodendrocytes were exposed to 2-AG at concentrations of $100,500,1$, and $2 \mu \mathrm{M}$ at time of plating on the CSPG matrix (\#CC117, $1 \mu \mathrm{g} / \mathrm{ml}$ ), and the cells were then cultured for $24 \mathrm{hr}$. Primary human oligodendrocytes were exposed to $2-A G$ at $2 \mu \mathrm{M}$ at the time of plating on the CSPG matrix (\#CC117, $1 \mu \mathrm{g} / \mathrm{ml}$ ) and then cultured for $24 \mathrm{hr}$.

\section{8 | Immunocytochemistry}

Treated and fixed astrocytes and oligodendrocytes that had been maintained in culture for $24 \mathrm{hr}$ were washed in $0.1 \mathrm{M}$ phosphate buffer (PBS), permeabilized in PBS $+0.2 \%$ Triton X-100 (Sigma Aldrich, Madrid, Spain) (PBT), and then blocked for $1 \mathrm{hr}$ at room temperature in blocking buffer (PBT plus $5 \%$ normal goat serum NGS: Vector Laboratories, Inc., Burlingame, CA). Rat astrocytes were then stained overnight at $4^{\circ} \mathrm{C}$ with antibodies against neurocan (\#1F6 mouse neurocan diluted 1:1,000, Developmental studies Hybridoma Bank, IA) and GFAP (\#G9269 rabbit GFAP diluted 1:1,000: Sigma-Aldrich, Madrid, Spain), while rat and human oligodendrocytes were stained with antibodies against O4 (\#MAB345, mouse IgM diluted 1:500: Millipore, Temecula, CA) and MBP (\#MAB382, mouse MBP diluted 1:250: Millipore, Temecula, CA). The following day, the cells were rinsed and then incubated for $1 \mathrm{hr}$ with the appropriate fluorescent secondary antibody (Molecular Probes Inc. Eugene, OR): Alexa 594 Fluor-conjugated goat anti-mouse antibody (for neurocan); Alexa 488 Fluor-conjugated goat anti-rabbit antibody (for GFAP); Alexa 488 Fluor-conjugated goat anti-mouse antibody (for MBP); Texas Red 568 Fluor-conjugated donkey anti-mouse IgM (for O4). Finally, the cells were counterstained with DAPI (Sigma Aldrich, Madrid, Spain).

\section{$2.9 \quad$ Western blotting}

After treatment, the cultured astrocyte were washed and lysed in RIPA buffer containing a complete protease inhibitor cocktail (Roche Diagnostics; Mannheim, Germany). To detect CSPGs, cell lysates were diluted in chondroitinase $A B C$ buffer $(50 \mathrm{mM}$ Tris [pH 8.0], $60 \mathrm{mM}$ sodium acetate and $0.02 \% \mathrm{BSA}$ ) and then treated for $3 \mathrm{hr}$ at $37^{\circ} \mathrm{C}$ with $0.1 \mathrm{U} / \mathrm{ml}$ chondroitinase $A B C$ from Proteus vulgaris (\#C3667, Sigma-Aldrich, Madrid Spain). To detect the CS56 signal, incubation with chondroitinase $A B C$ was omitted. The reaction was stopped by adding $5 \times$ Laemmli sample buffer and boiling for $5 \mathrm{~min}$. Equal amounts of protein $(15 \mu \mathrm{g})$ were resolved on a $6 \%$ sodium dodecyl sulfate-polyacrylamide gel (SDS-PAGE) to examine CSPGs and on a 10-12\% SDS-PAGE for signaling proteins, and then transferred to a nitrocellulose membrane at $4{ }^{\circ} \mathrm{C}$ (Amersham Biosciences, Piscataway, NJ). The membranes were washed with TBS and TBS with $0.1 \%$ Tween 20 (TBST), and then blocked for $1 \mathrm{hr}$ in LI-COR blocking solution. After blocking, the membranes were washed in TBST and probed overnight with antibodies against: neurocan (\#1F6, mouse, Developmental studies Hybridoma Bank), brevican (\#610894, mouse, BD Bioscience, San Diego, CA), SMAD2 (\#MAS-15112, mouse, Thermofisher, MA), pSMAD2 (\#3108, rabbit, Cell Signaling, MA), SMAD3 (\#Ab75512, mouse, Abcam, Cambridge, UK) and p-SMAD3 (\#9520, rabbit, Cell Signaling, MA), all diluted 1:1,000; and CS-56 diluted 1:500 (\#C8035, mouse IgM, Sigma-Aldrich, Madrid, Spain). The membranes were then washed in blocking solution and incubated for $1 \mathrm{hr}$ with the secondary conjugated fluorophores diluted 1:15,000 (IRDye $800 \mathrm{CW}$ anti-mouse; IRDye 680LT antimouse IgM; IRDye $680 \mathrm{LT}$ anti-rabbit). The membranes were then washed again with TBST and TBS, and the signal was detected on an Odyssey ${ }^{\circledR}$ CLx Imaging System (LI-COR Biotechnology, Germany). The signals were normalized to those obtained for tubulin (\#T5168, mouse diluted 1:10,000, Sigma-Aldrich, Madrid, Spain) or pan-actin (\#D18C11, rabbit diluted 1:1,000, Cell Signaling, MA), and NewBlot IR Stripping (LI-COR) reagent was used for the stripping procedure performed for $30 \mathrm{~min}$ at room temperature. 


\subsection{0 | ImageXpress acquisition}

Images of the 96-well plates of primary human oligodendrocytes processed for immunocytochemistry were obtained on a Molecular Device ImageXpress high-content imaging system. The images were collected at $10 \times$ from six fields per well, with appropriate absorption and emission wavelengths for each secondary antibody.

\subsection{Image processing and analysis}

The images of rat $\mathrm{O} 4$ and MBP immunostained oligodendrocytes were acquired on a Leica TCS SP5 confocal microscope. Briefly, $2 \mu \mathrm{m}$ step size confocal stacks were captured in the z-direction from all cells in 4-5 fields per well and experimental condition, using $20 \times$ objectives, with 2-3 replicates per condition and 3-5 independent experiments were performed. The same threshold was set for all the cells and all the experimental conditions. Oligodendrocyte morphology was studied using the Analyze Skeleton plugin of the ImageJ software (NIH, Bethesda, MD) according to the guidelines of Morrison and Filosa (2013). Confocal images were acquired and the maximum intensity projection of the $\mathrm{O} 4$ or MPB positive channel was used as a noise filter to eliminate single-pixel background fluorescence, converting the resulting images to a binary image in order to skeletonize it use the ImageJ software. All the cells per field and image were analyzed and averaged to a single data point for each replicate and condition, collecting the data for the number of branches (total number of ramifications), joints (bifurcations of ramifications), and end-points (final points of the ramifications) as a morphological measure of oligodendrocyte complexity. The number of cells per field corresponds to the average of the images per condition.

\subsection{Reverse transcription (RT) and real- time PCR}

Total RNA was extracted from rat astrocyte cultures using RNeasy mini columns (Qiagen, Manchester, UK), avoiding genomic DNA contamination by DNase I degradation (DNase I, Sigma-Aldrich). The RNA yield was determined using a Nanodrop spectrophotometer (Thermo Scientific; Wilmington, DE) and the total RNA (1 $\mu \mathrm{g}$ in $20 \mu \mathrm{l})$ was reverse transcribed into cDNA using poly-dT primers and a reverse transcription kit (Promega Biotech Ibérica, S.L., Madrid, Spain). Realtime PCR was carried out with SYBR ${ }^{\circledR}$ using the followed oligonucleotide primer sequences (Applied Biosystems, Warrington, UK): XT-1 forward 5'- GGGAATGCAGAAATGGGGGA-3', XT-1 reverse 5'GAAGGTCAGAGGTGCGACAA-3'; XT-2 forward 5'-GGGTGAGACCC GCTTCCT-3', XT-2 reverse 5'-CTGAGAGGTAGTTTGCGGTTG-3'; C4ST forward 5'-GGCGCTGCTGGAAGTGAT-3', C4ST reverse 5-AAGATAAAGGATCCGAAGCAA-3'; Brevican forward 5'-CCATCC AGAACCCACGAGA-3', Brevican reverse 5'-ACCCACCACTCC GTAATTCC-3'; 18S forward 5'-ATGCTCTTAGCTGAGTGTCCCG-3', $18 \mathrm{~S}$ reverse $5^{\prime}$-ATTCCTAGCTGCGGTATCCAGG-3'. After an initial incubation at $50^{\circ} \mathrm{C}$ for $2 \mathrm{~min}$ and $95^{\circ} \mathrm{C}$ for $10 \mathrm{~min}, \mathrm{PCR}$ amplification was performed over 40 cycles of $95^{\circ} \mathrm{C}$ for $15 \mathrm{~s}$ and $60^{\circ} \mathrm{C}$ for $1 \mathrm{~min}$. The samples were assayed in triplicate on an Applied Biosystems PRISM 7500 Sequence detection system. To rule out genomic DNA contamination, a control sample using RNA that had not been reversed transcribed was used as the template for each set of extractions. Gene expression was calculated using the $2^{-\Delta \Delta C t}$ method and the relative expression was quantified by calculating the ratio between the values obtained for each gene of interest and those of the $18 \mathrm{~S}$ gene. The results are expressed as a percentage with respect to the control group.

\section{$2.13 \mid$ ELISA}

The neurocan and brevican levels in supernatants from primary rat astrocyte cell cultures were measured using specific solid-phase sandwich ELISA kits with antibodies against neurocan and brevican respectively, following the manufacturer's recommendations: for neurocan rat astrocytes - \#MBS 450382, My Biosource, San Diego, CA; and for brevican rat astrocytes \#MBS732282, My Biosource, San Diego, $\mathrm{CA}$. The neurocan levels in human astrocyte cell cultures were measured by the ELISA kit CSB-EL015513HU Cusabio, Houston, TX, following the manufacturer's recommendations. The minimum detectable concentration of rat neurocan was $0.055 \mathrm{ng} / \mathrm{ml}$, the detection range was $0.156-10 \mathrm{ng} / \mathrm{ml}$, and the intra- and inter-coefficient of variation was 10 and $12 \%$, respectively. The sensitivity of the brevican assay is $1.0 \mathrm{pg} / \mathrm{ml}$. The detectable limit of human neurocan was $0.078 \mathrm{ng} / \mathrm{ml}$, the detection range was $0.312-20 \mathrm{ng} / \mathrm{ml}$, and the intraand inter-coefficient of variation was 8 and $10 \%$, respectively.

\subsection{4 | Statistical analysis}

All the data are expressed as the mean \pm SEM, using the IBM SPSS 24 statistical software (Inc- IBM, Chicago, IL) for the statistical analysis. One-way ANOVA followed by the Bonferroni and Tukey's post hoc tests, or a nonparametric Kruskal-Wallis test was employed for multiple comparisons. The level of significance was set at $p \leq .05$.

\section{$3 \mid$ RESULTS}

\subsection{2-AG treatment diminishes the expression of enzymes involved in the synthesis of CSPGs and the levels of neurocan and brevican in rat astrocytes cultures}

CSPGs consist of a core protein with attached sulfate GAG side chains (Susarla et al., 2011). The synthesis of the GAG chain is carried out by different xylol transferases (XT-1 and XT-2) that constitute the rate-limiting step of GAG synthesis and by the chondroitin 4 sulfotransferase (C4ST). Here first, we show that stimulated 
astrocytes by TGF- $\beta 1 / \mathrm{bFGF}$ display elevated expression of XT-1 $(p<.001$ vs. CTL), XT-2 ( $p<.01$ vs. CTL) and C4ST ( $p<.001$ vs. CTL) transcripts at $6 \mathrm{hr}$ of the incubation period (Figure 1a). The exposure of 2-AG (100 nM) reduced the mRNA expression of C4ST $(p<.05$ vs. TGF- $\beta 1 / \mathrm{bFGF}$ ) at $6 \mathrm{hr}$ but at $24 \mathrm{hr}$ the increased expression of XT-1 $(p<.01$ vs. CTL) was blunted by the presence of the endocannabinoid ( $p<.01$ vs. TGF- $\beta 1 / \mathrm{bFGF}$ ). This is reflected in the reduced gene expression of brevican at the dose of $100 \mathrm{nM} 2-\mathrm{AG}$, whereas a higher dose of 2-AG $(500 \mathrm{nM})$ was less efficacious as it is shown in Figure 1a. A dose-response curve of neurocan and brevican protein production (Figure 1 b) reveals that 2-AG $10 \mathrm{nM}$ did not avoid the release of neurocan and brevican at the extracellular (a)
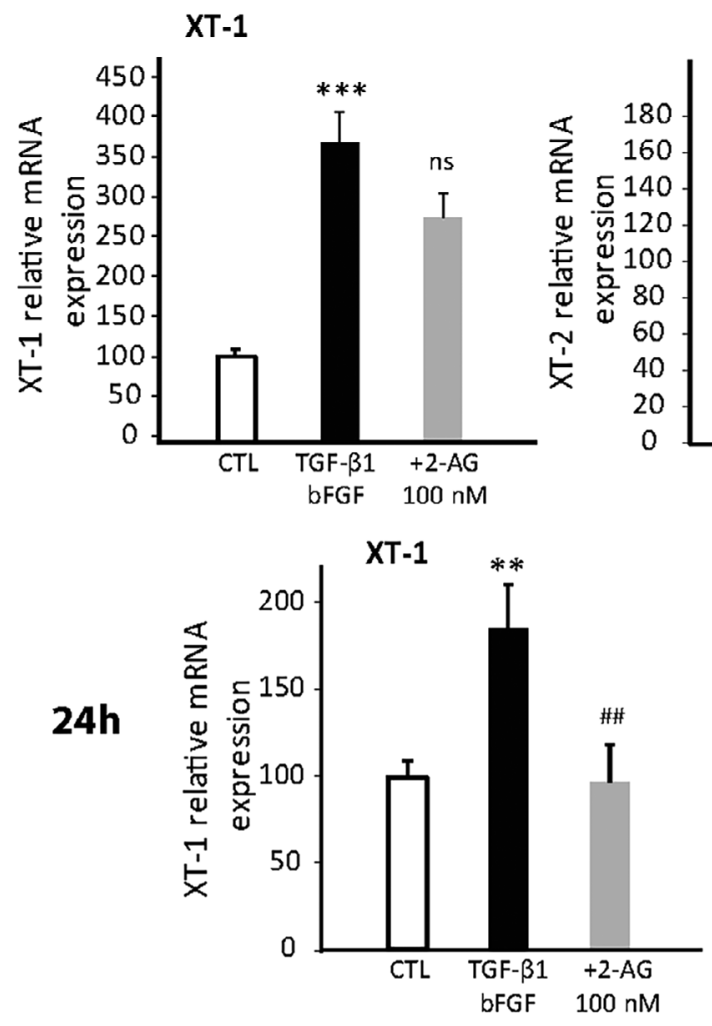

(b)

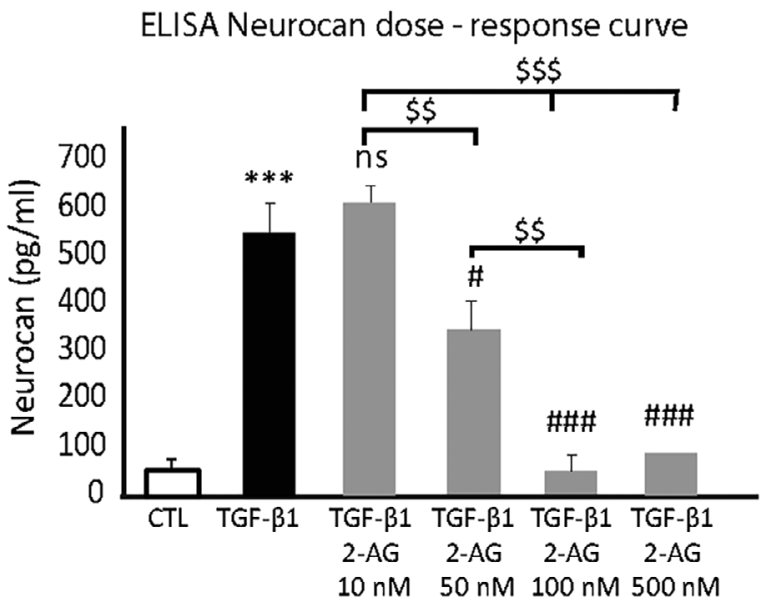

$\mathrm{XT}-2$
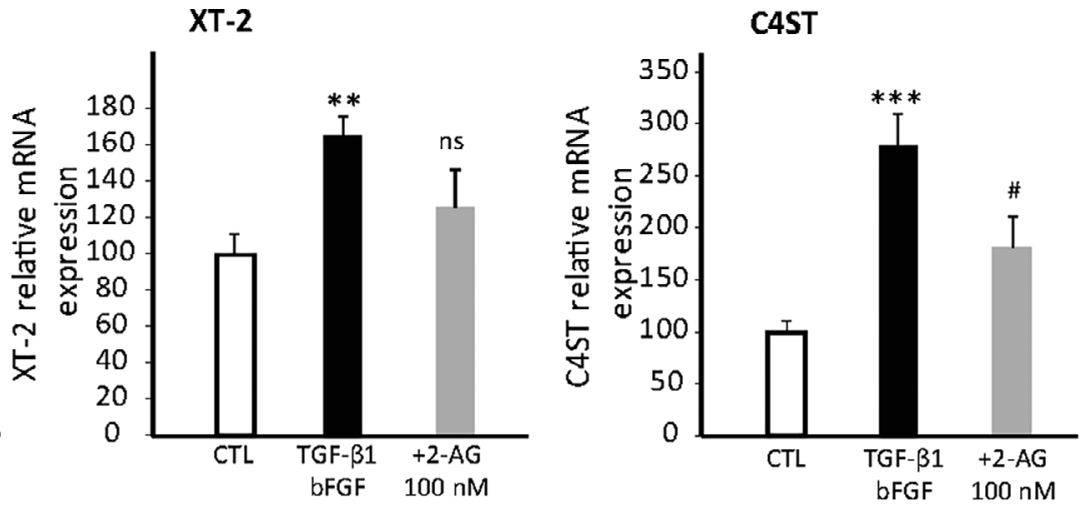

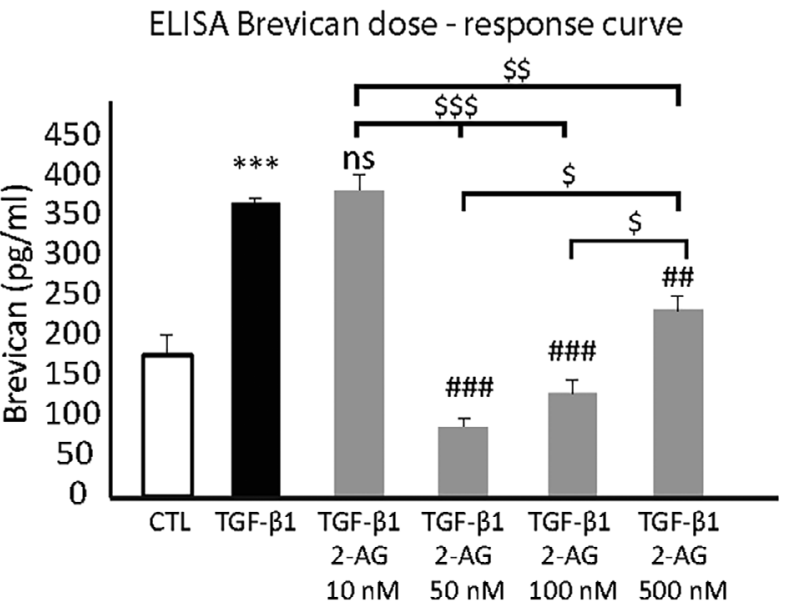

FIGURE 1 2-AG treatment reduces the expression of enzymes involved in CSPGs synthesis and the levels of neurocan and brevican in cultured rat astrocytes. (a) RT-PCR analysis of brevican and XT-1, XT2, C4ST enzymes in cell lysates from cultured astrocytes stimulated with TGF- $\beta 1(20 \mathrm{ng} / \mathrm{ml})$ and bFGF $(10 \mathrm{ng} / \mathrm{ml})$ and treated with 2-AG (100 and $500 \mathrm{nM})$ for 6 and $24 \mathrm{hr}$. (b) ELISA analysis of extracellular neurocan and brevican production by rat astrocytes stimulated with TGF- $\beta 1(20 \mathrm{ng} / \mathrm{ml})$ and treated with 2-AG $(10,50,100$, and $500 \mathrm{nM})$ for $24 \mathrm{hr}$. The data

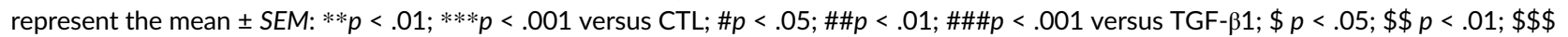
$p<.001$ versus 2-AG treated cells; ns, not significant. One-way ANOVA applied followed by the Bonferroni and Tukey's post hoc tests for ELISAs analysis and western blot brevican analysis. Nonparametric Kruskal-Wallis test was applied to analyze RT-PCRs (4-5 independent experiments, 3 replicates per experiment). 2-AG, 2-arachidonoylglycerol; CSPGs, chondroitin sulfate proteoglycans 
media of astrocyte cultures. However, although the rest of the doses were effective in diminishing CSPGs release, the maximal effect of 2-AG for the two CSPGs is achieved by the dose of $100 \mathrm{nM}$ $(p<.001$ vs. TGF- $\beta 1$ ). These results indicate that the endocannabinoid 2-AG directly interferes with the synthesis of CSPGs in astrocyte cultures.

\section{2 | 2-AG-induced reduction of neurocan is} dependent on the CB2 signaling system in astrocyte cultures

Astrocytes are the main source of CSPGs (Alonso \& Privat, 1993;

Fawcett \& Asher, 1999; Reier \& Houle, 1988; Silver \& Miller, 2004; (a)

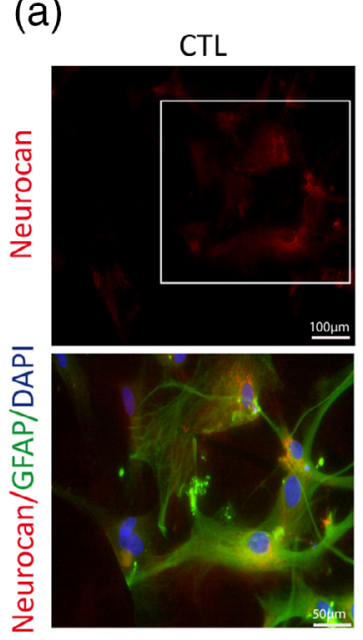

(b)

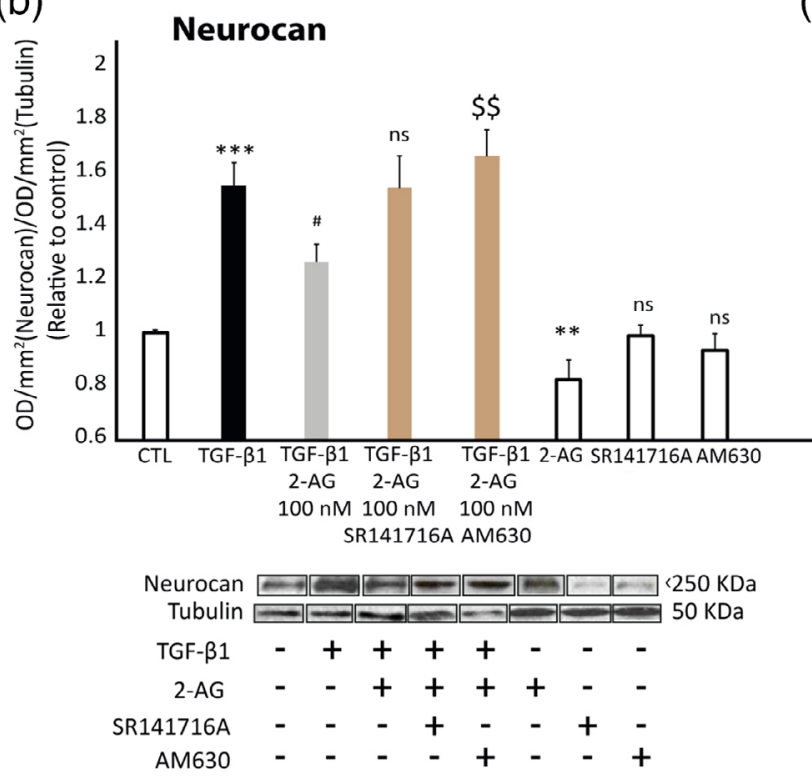

(d)
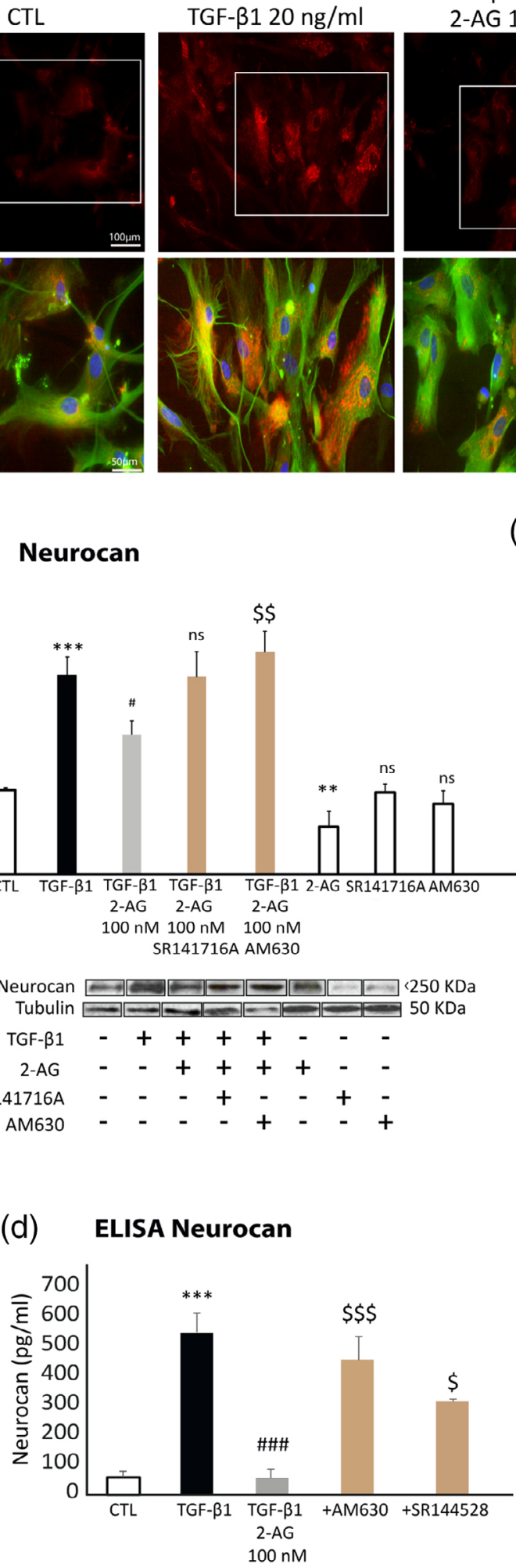

TGF- $\beta 120 \mathrm{ng} / \mathrm{ml}$
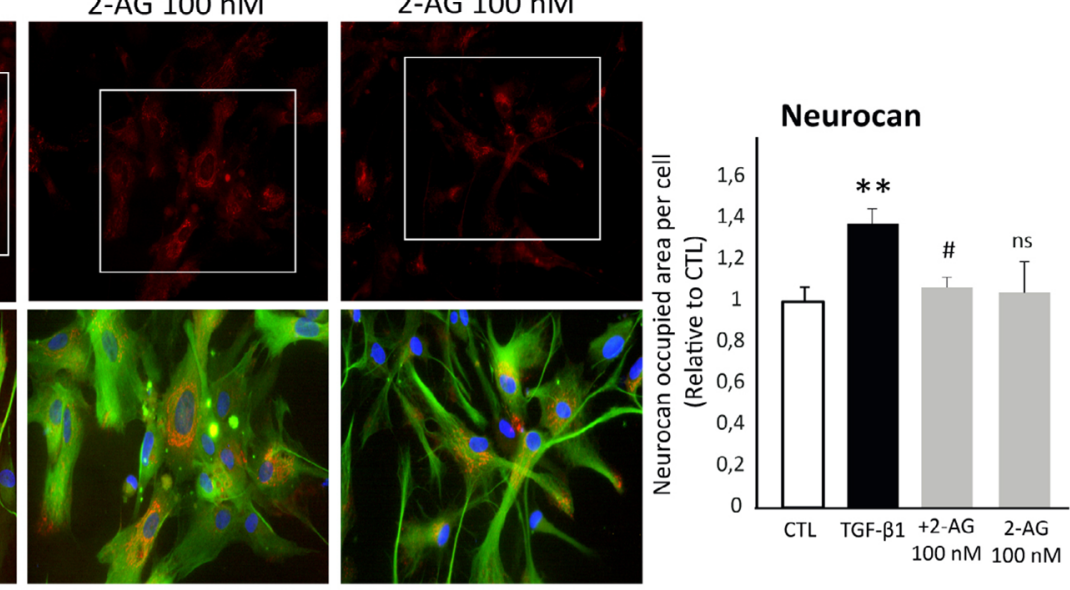

(c)

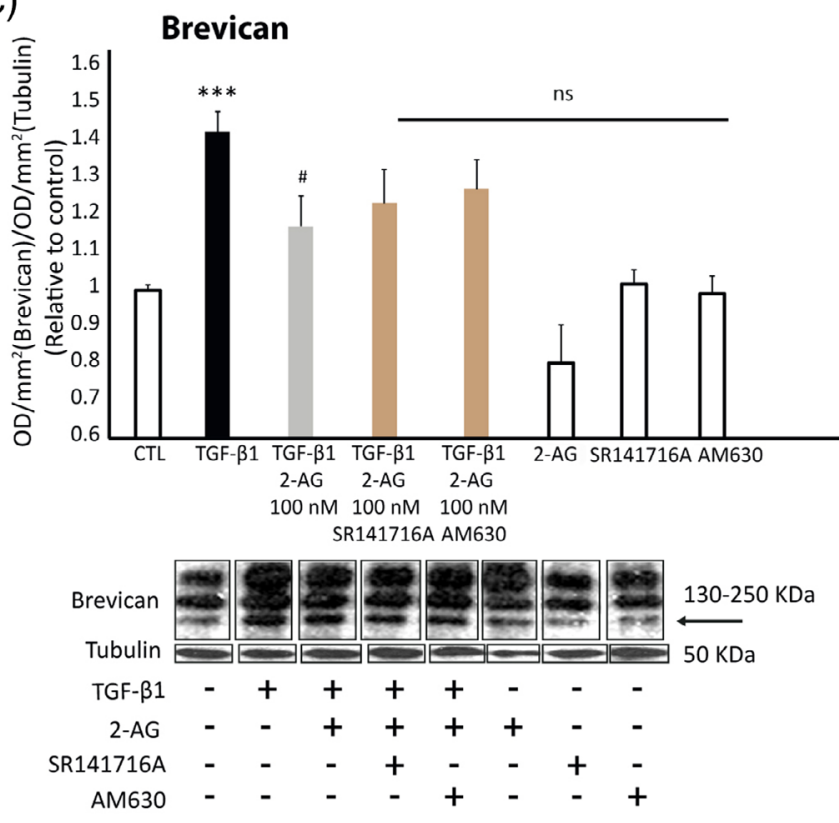

(e)

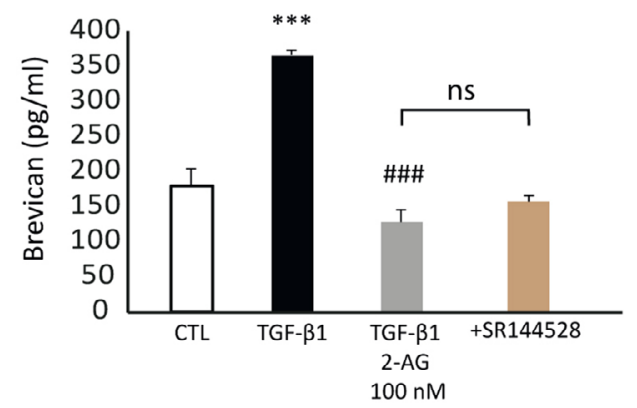

FIGURE 2 Legend on next page. 
Susarla et al., 2011), the production of which is stimulated by TGF- $\beta 1$ in vivo and in vitro (Hamel, Mayer, \& Gottschall, 2005; Silver \& Miller, 2004; Susarla et al., 2011; Yu, Wang, Katagiri, \& Geller, 2012). Immunocytochemical staining for neurocan was weaker in astrocytes exposed to 2-AG (100 nM) for $24 \mathrm{hr}$ as indicated the quantification of the neurocan occupied area per cell (Figure 2a). In addition, less neurocan (Figure 2b), and brevican (Figure $2 \mathrm{c}$ ) was detected by western blots following the treatment of 2-AG $100 \mathrm{nM}$. To assess the receptors involved in this effect of 2-AG, CB1R (SR141716A, $1 \mu \mathrm{M})$ and CB2R (AM630, $1 \mu \mathrm{M}$ or SR144528, $1 \mu \mathrm{M}$ ) antagonists were administered $30 \mathrm{~min}$ prior to 2-AG treatment. The reduction of neurocan production in response to $2-A G$ was prevented significantly by prior exposure to the $\mathrm{CB} 2 \mathrm{R}$ antagonist (Figure $2 \mathrm{~b}$ ). Furthermore, exposure of 2-AG alone, without TGF- $\beta 1$ stimulation did not produce any increase in CSPGs but rather, there was a reduction in neurocan relative to the control condition. Similarly, no effect was observed when cannabinoid receptor antagonists were administered alone. To further confirm the relevance of CB2R signaling system in neurocan reduction, we carried out a set of experiments in which we assessed the levels of neurocan in the extracellular media (Figure 2d) confirming that the blockade of CB2R by AM630, but also by SR2 (SR144528) reverted significantly 2-AG-induced reduction of neurocan ( $p<.001$ vs. TGF- $\beta 1+2$ AG 100 nM for AM630 and $p<.05$ vs. TGF- $\beta 1+2$ AG $100 \mathrm{nM}$ for SR2). The ELISA results for brevican (Figure 2e) confirm the immunoblot data, indicating that $C B 2$ receptors are not involved in 2-AG-induced reduction of brevican.

\section{3 | The increase in 2-AG tone by inhibiting} hydrolyzing enzymes dampens neurocan and brevican expression, diminishing the extracellular levels of both CSPGs

We further assessed how 2-AG affects CSPG production by increasing its tone through exposure to inhibitors of 2-AG hydrolysis by the MAGL and ABHD6 enzymes. As such, TGF- $\beta 1$ stimulated astrocytes were treated for $24 \mathrm{hr}$ with two MAGL inhibitors (the reversible inhibitor UCM03025, $1 \mu \mathrm{M}$, and an irreversible inhibitor JZL184, $1 \mu \mathrm{M}$ ), and one inhibitor of the ABHD6 enzyme (WWL70, $10 \mu \mathrm{M})$. The generation of neurocan (Figure $3 a$ ) and brevican (Figure $3 b$ ) was reduced significantly by inhibitors of 2-AG hydrolysis when measured by western blots. ELISA results confirm immunoblot data. Thus, extracellular neurocan (Figure 3c) was also significantly diminished in astrocytes exposed to MAGL inhibitors ( $p<.001$ vs. TGF- $\beta 1$ ) and to the ABHD6 inhibitor WWL70 ( $p<.05$ vs. TGF- $\beta 1$ ) although in that case in less degree than in the case of the MAGL inhibitor JLZ ( $p<.05$ vs. TGF$\beta 1+J L Z$ ). Extracellular brevican levels (Figure 3d) were also significantly diminished by all the 2-AG hydrolysis enzymes $(p<.001$ vs. TGF- $\beta 1$ ).

\subsection{2-AG treatment reduces the phosphorylation of SMAD2 in TGF- $\beta 1$ treated astrocytes, an effect possibly mediated through CB2 receptor signaling}

The TGF- $\beta 1-S M A D$ pathway is a canonical signaling pathway involved in CSPG synthesis by cultured astrocytes (Schachtrup et al., 2010; Susarla et al., 2011). To assess how 2-AG provokes a reduction in CSPGs, we examined the phosphorylation of SMAD2 and SMAD3 in TGF- $\beta 1$ stimulated astrocytes treated with 2-AG (100 nM) for $1 \mathrm{hr}$, assessing the potential involvement of the CB1R and CB2R through the addition of specific antagonists (SR141716A, $1 \mu \mathrm{M}$ and AM630, $1 \mu \mathrm{M}) 30$ min prior to $2-A G$ treatment. Our results confirmed that the TGF- $\beta 1-S M A D$ signaling pathway is activated in the stimulated astrocytes as the phosphorylation of both SMAD2 and SMAD3 proteins was enhanced in these conditions (Figure 4a,b). SMAD2 phosphorylation was significantly dampened by $2-A G$ treatment, yet it reverted to TGF- $\beta 1$ levels in cells also exposed to the CB2R antagonist (Figure 4a). No significant effect was observed in the case of SMAD3 phosphorylation (Figure 4b).

\subsection{2-AG treatment reduces CSPG expression and extracellular neurocan levels in human astrocytes in culture}

Human astrocytes are known to synthesize CSPGs in culture when stimulated (Keough et al., 2016), so we examined the CSPGs produced by primary human astrocytes isolated from therapeutically aborted human fetuses that were treated for $24 \mathrm{hr}$ with TGF- $\beta 1(10 \mathrm{ng} / \mathrm{ml})$ and $2-\mathrm{AG}$ at concentrations of 10,50 , and $100 \mathrm{nM}$. In western blots probed with the CS-56 antibody, the expression of CSPGs was induced in TGF- $\beta 1$ stimulated astrocytes, although this effect was significantly weakened by the administration of 2-AG at 50 and $100 \mathrm{nM}$

FIGURE 2 2-AG treatment reduces the expression of CSPGs in cultured rat astrocytes and the reduction in neurocan is dependent on the CB2 receptor signaling. Cultured astrocytes were stimulated with TGF- $\beta 1(20 \mathrm{ng} / \mathrm{ml})$ and treated with 2-AG (100 nM) for $24 \mathrm{hr}$.

(a) Representative immunocytochemistry of neurocan (red) and GFAP (green) in primary astrocytes together with the quantification of neurocan expression. Western blots of cell lysates probed for (b) neurocan and (c) brevican. ELISA analysis of extracellular neurocan (d), and brevican (e) production by rat astrocytes stimulated with TGF- $\beta 1(20 \mathrm{ng} / \mathrm{ml})$ and treated with 2-AG $(100 \mathrm{nM})$, and CB2R antagonists for $24 \mathrm{hr}$. CB1R (SR141716A, $1 \mu \mathrm{M}$ ) and CB2R (AM630, $1 \mu \mathrm{M}$ and SR144528, $1 \mu \mathrm{M}$ ) antagonists were added 30 min before 2-AG. Scale bar: 50 and $100 \mu \mathrm{m}$. The data represent the mean \pm SEM: $* * p<.01 ; * * * p<.001$ versus CTL; $\# p<.05 ; \# \# \# p<.001$ versus TGF- $\beta 1 ; \$ p<.05 ; \$ \$ p<.01 ; \$ \$ p<.001$ versus TGF- $\beta 1$ + 2-AG; ns, not significant. One-way ANOVA applied followed by the Bonferroni and Tukey's post hoc tests for ELISAs analysis and western blot brevican analysis. A nonparametric Kruskal-Wallis test was applied to analyze neurocan by western-blot (5-6 independent experiments, 3 replicates per experiment). 2-AG, 2-arachidonoylglycerol; CSPGs, chondroitin sulfate proteoglycans 
(a)

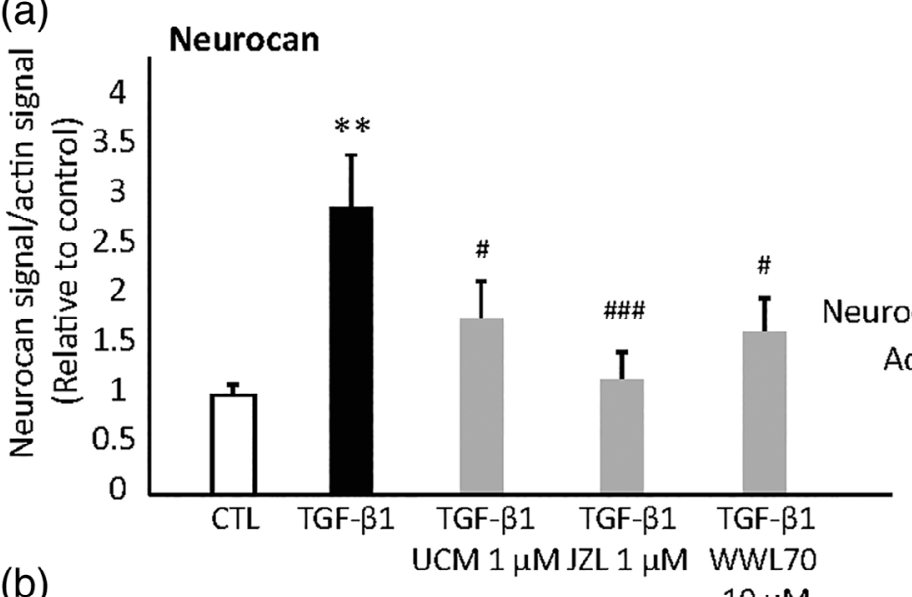

(b)

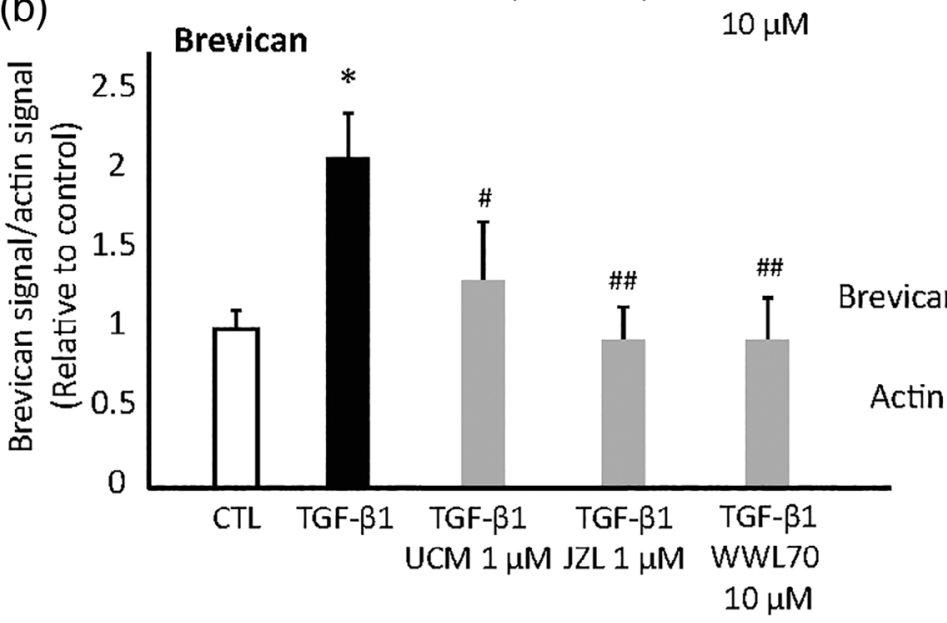

TGF- $\beta 1$ TGF- $\beta 1$ TGF- $\beta 1$

UCM JZL WWL70

CTL TGF-B1 $1 \mu \mathrm{M} \quad 1 \mu \mathrm{M} \quad 10 \mu \mathrm{M}$

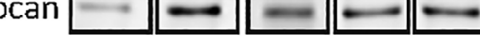

$250 \mathrm{KDa}$

Actin

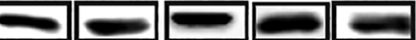

$45 \mathrm{KDa}$

(c)

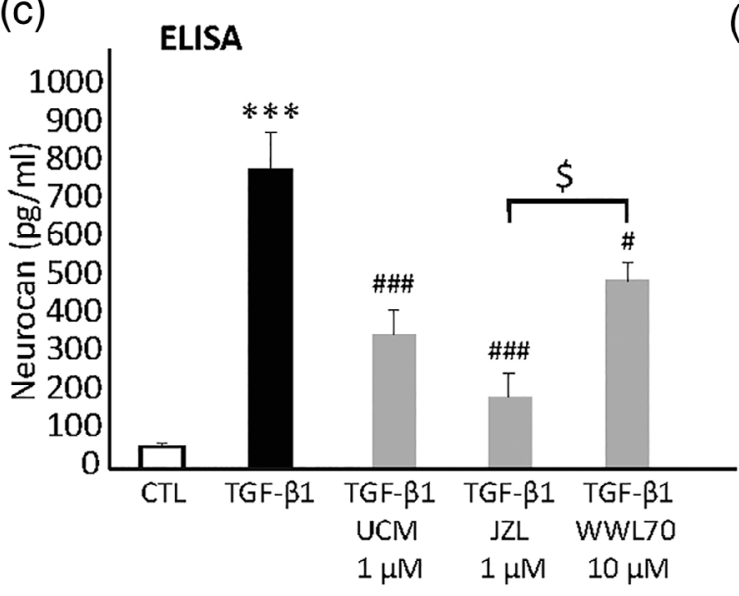

(d)

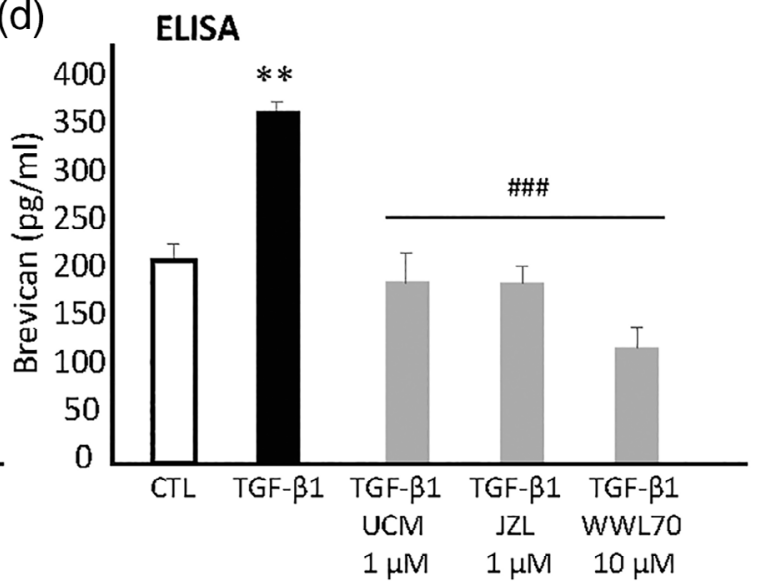

FIGURE 3 Inhibitors of 2-AG hydrolysis reduce neurocan and brevican expression and its extracellular levels by cultured rat astrocytes. Rat astrocytes were stimulated with TGF- $\beta 1(20 \mathrm{ng} / \mathrm{ml})$ and treated for $24 \mathrm{hr}$ with two MAGL inhibitors (the reversible, UCM03025 [1 $\mu$ M] or the irreversible, JZL $184[1 \mu \mathrm{M}]$ ) or an inhibitor of the ABHD6 enzyme (WWL70 [10 $\mu \mathrm{M}]$ ). Both neurocan and brevican expression and its extracellular levels were analyzed by western blots ( $a$ and b, respectively) and ELISA assays (c and d, respectively). The data represent the mean

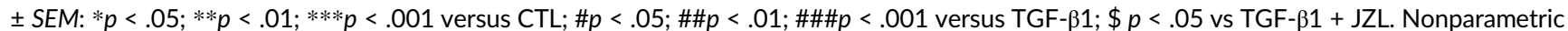
Kruskal-Wallis test for western-blot analysis and one-way ANOVA applied followed by the Bonferroni and Tukey's post hoc tests for ELISAs analysis (4-5 independent experiments with 3 replicates per experiment)

(Figure 5a). In addition, there was less extracellular neurocan evaluated by ELISA measurement when astrocytes were exposed to 2-AG (Figure $5 b$ ), in that case, extracellular levels of neurocan were diminished by 2AG $10 \mathrm{nM}$ and the levels of neurocan were negligible by the doses of 2-AG 50 and $100 \mathrm{nM}$. These results suggest that human astrocytes may be most sensitive to the actions of 2-AG. 
(a)
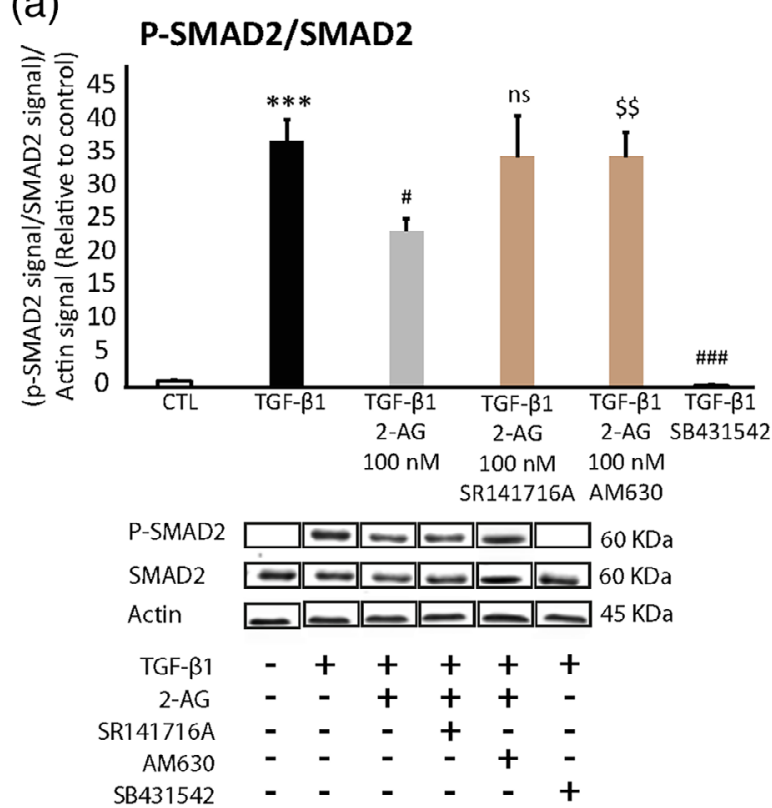

(b)
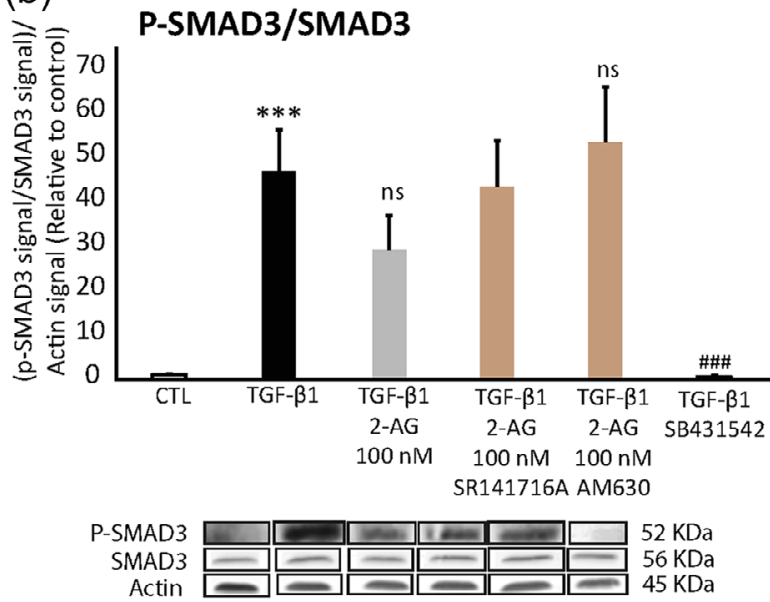

$\begin{array}{rcccccc}\mathrm{TGF}-\beta 1 & - & + & + & + & + & + \\ 2-A G & - & - & + & + & + & - \\ \mathrm{SR} 141716 \mathrm{~A} & - & - & - & \mathbf{+} & - & - \\ \mathrm{AM} 630 & - & - & - & - & + & - \\ \mathrm{SB} 431542 & - & - & - & - & - & +\end{array}$

FIGURE 4 2-AG dampens SMAD2 phosphorylation in TGF- $\beta 1$ treated astrocytes, an effect possibly mediated through CB2 signaling. Astrocytes were stimulated with TGF- $\beta 1(20 \mathrm{ng} / \mathrm{ml})$ and treated with 2-AG $(100 \mathrm{nM})$ for $1 \mathrm{hr}$. The phosphorylation of SMAD2 and SMAD3 proteins were analyzed by western blots. CB1R (SR141716A $1 \mu \mathrm{M})$ and CB2R (AM630 $1 \mu \mathrm{M})$ antagonists were added 30 min before 2-AG administration, and SB431542 $(20 \mu \mathrm{M})$ was used to inhibit SMAD signaling. The data represent the mean \pm SEM: $* * * p<.001$ versus CTL; $\# p<.05$ versus TGF- $\beta 1$; \#\#\#p <.001; \$ $p<.01$ versus TGF- $\beta 1+2-A G$. ns, not significant. Nonparametric Kruskal-Wallis test (four independent experiments, three replicates per experiment). 2-AG, 2-arachidonoylglycerol [Color figure can be viewed at wileyonlinelibrary.com]
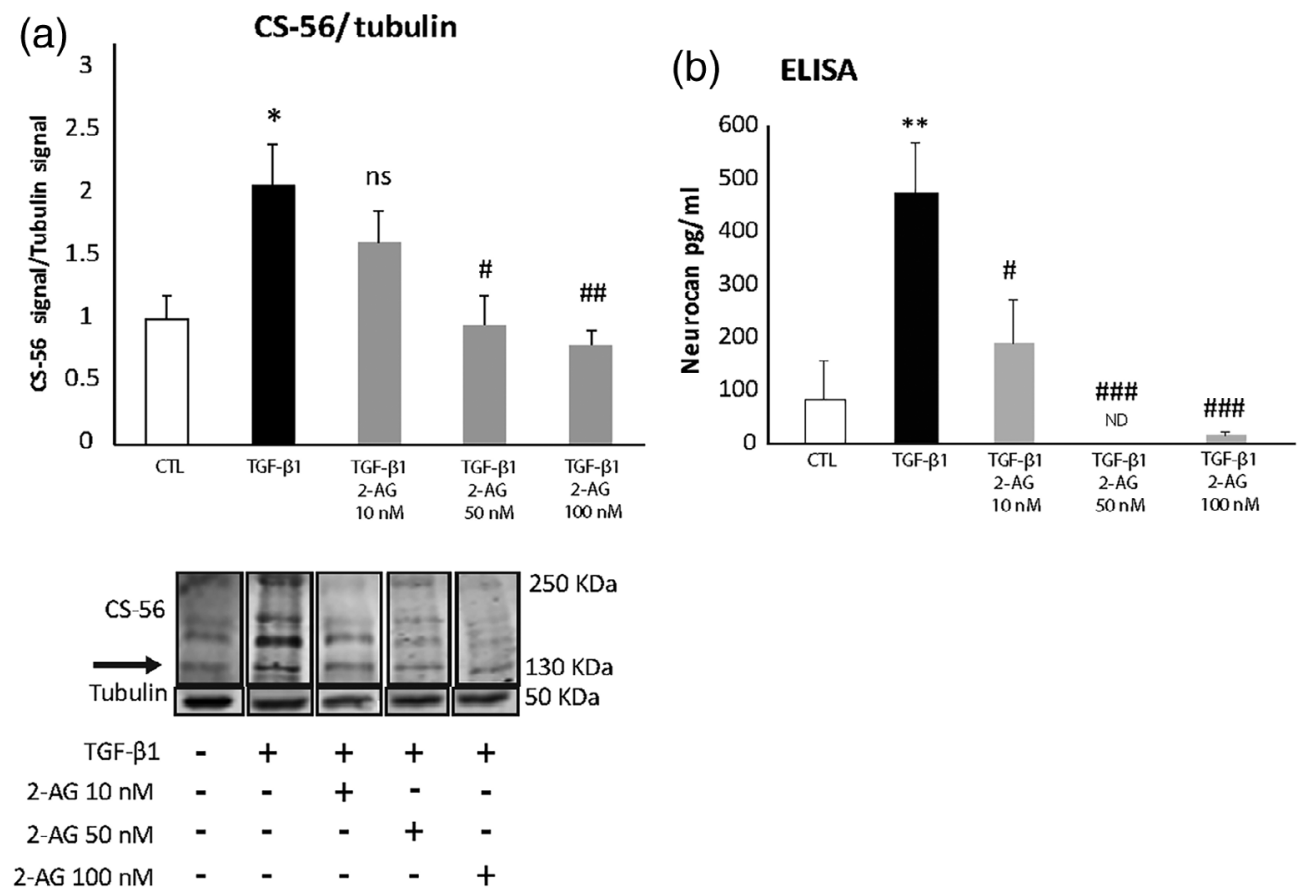

FIGURE 5 Treatment with 2-AG reduces CSPG expression and neurocan extracellular levels by cultured human astrocytes. (a) Expression of CSPGs by human fetal astrocytes evaluated by probing western blots with the CS-56 antibody and (b) neurocan secretion evaluated by ELISA in human fetal astrocytes stimulated with TGF- $\beta 1(10 \mathrm{ng} / \mathrm{ml})$ and treated for $24 \mathrm{hr}$ with 2-AG at a concentration of 10, 50, and $100 \mathrm{nM}$. The data

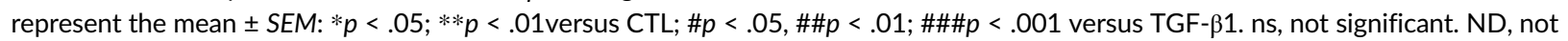
detectable. One-way ANOVA test followed by the Bonferroni and Tukey's post hoc tests (four independent experiments, three replicates per experiment). 2-AG, 2-arachidonoylglycerol; CSPGs, chondroitin sulfate proteoglycans 
(a)
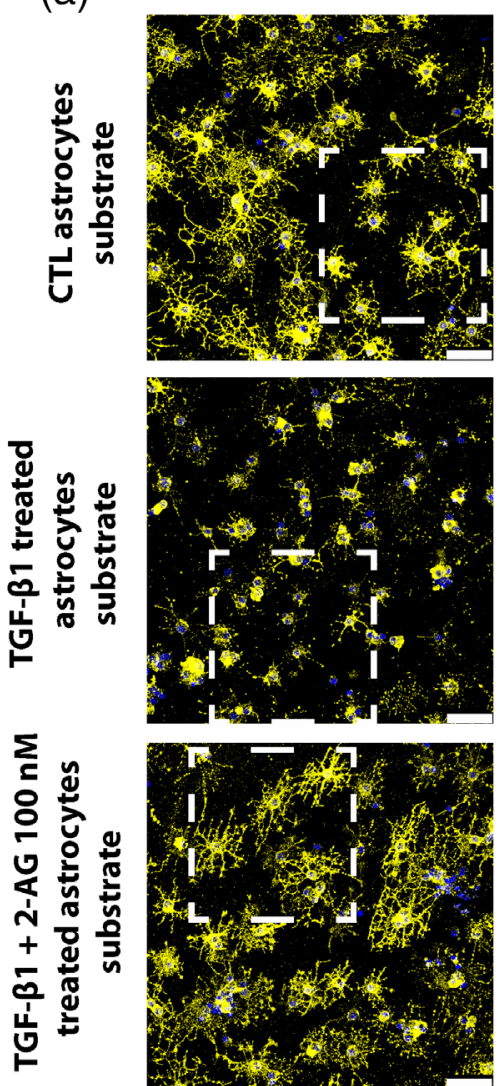
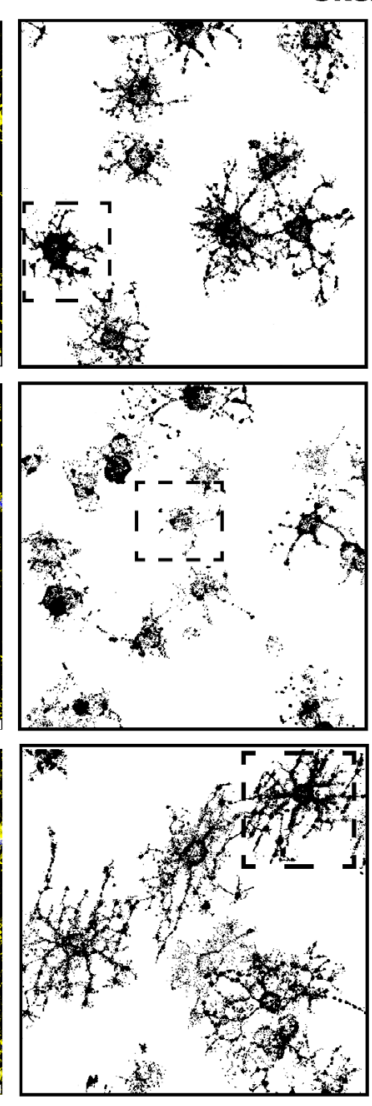

Skeleton
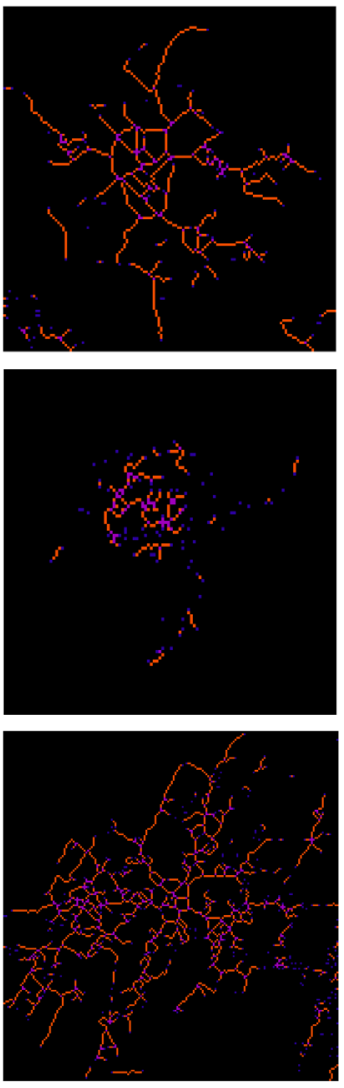

(b) Number of $\mathrm{O} 4$ positive cells

\section{(c)

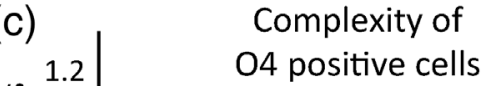 \\ O4 positive cells}

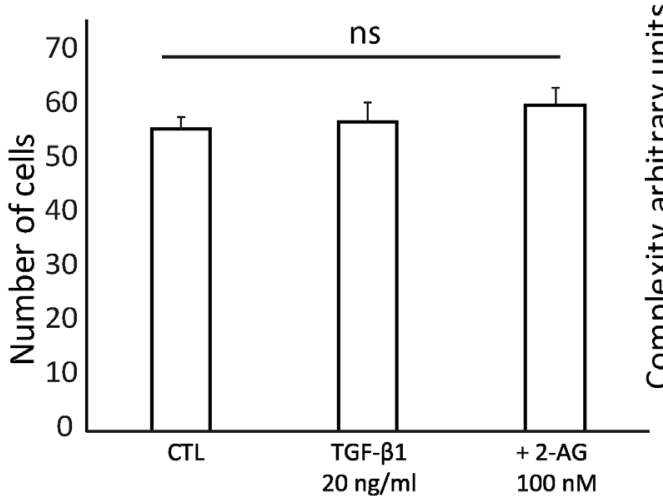

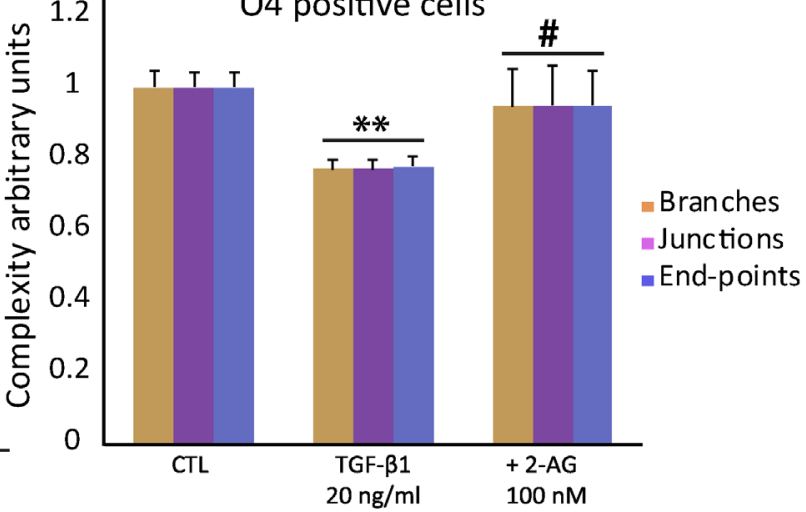

FIGURE 6 The 2-AG treated astrocyte matrix is less inhibitory for oligodendrocyte differentiation. Rat oligodendrocytes cultured for 24 hr on a matrix generated by rat astrocytes stimulated with TGF- $\beta 1(20 \mathrm{ng} / \mathrm{ml})$ and treated with 2-AG (100 nM) for 24 hr. (a) Representative immunocytochemistry for $\mathrm{O} 4$ (yellow) and DAPI (blue), and their respective skeletons. (b) The number of O4 positive cells/field. (c) Branches, junctions, and end-points obtained from the skeleton data. Scale bar: $50 \mu \mathrm{m}$. The data represent the mean \pm SEM: **p<.01 versus CTL; \#p $<.05$ versus TGF- $\beta 1$. ns, not significant. One-way ANOVA test followed by the Bonferroni and Tukey's post hoc tests (three independent experiments, three replicates per experiment). 2-AG, 2-arachidonoylglycerol

\section{6 | The matrix generated by astrocytes exposed to 2-AG is less inhibitory to oligodendrocyte differentiation}

We next tested the effect of restricting rat astrocyte CSPG synthesis on rat OPC differentiation in culture. As such, we seeded astrocytes in 24-well plates and treated them with TGF- $\beta 1(20 \mathrm{ng} / \mathrm{ml})$ and 2-AG $(100 \mathrm{nM})$ for $24 \mathrm{hr}$ to alter the proportion of CSPGs in the ECM secreted and deposited on the base of the plate. After treatment and in order to avoid any effect produced by cell-cell contact between astrocytes and OPCs, astrocytes were removed from the plate using Versene $(0.2 \mathrm{~g} / \mathrm{ml}$ EDTA). Rat OPCs were then plated on the ECM 

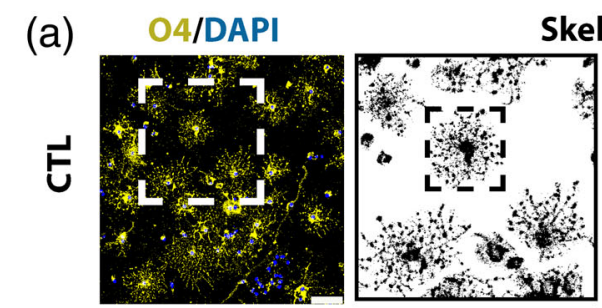

Seleton
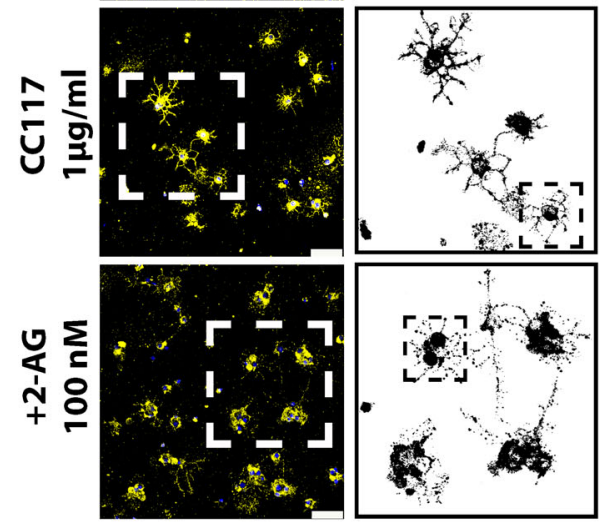

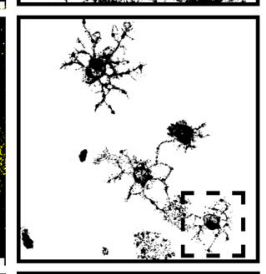

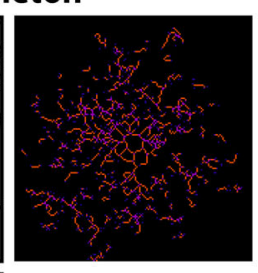
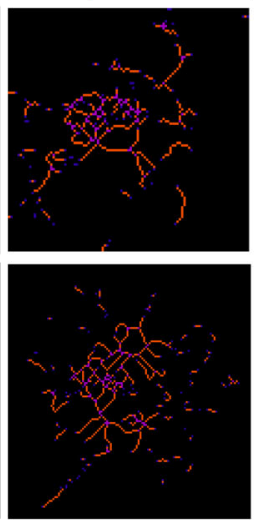
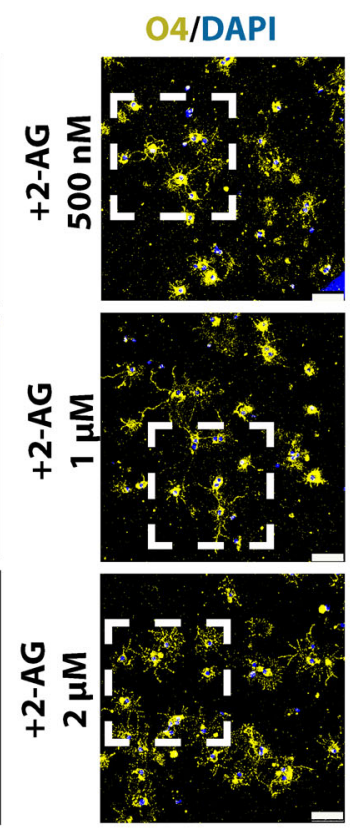

(c)

(c) 1.1

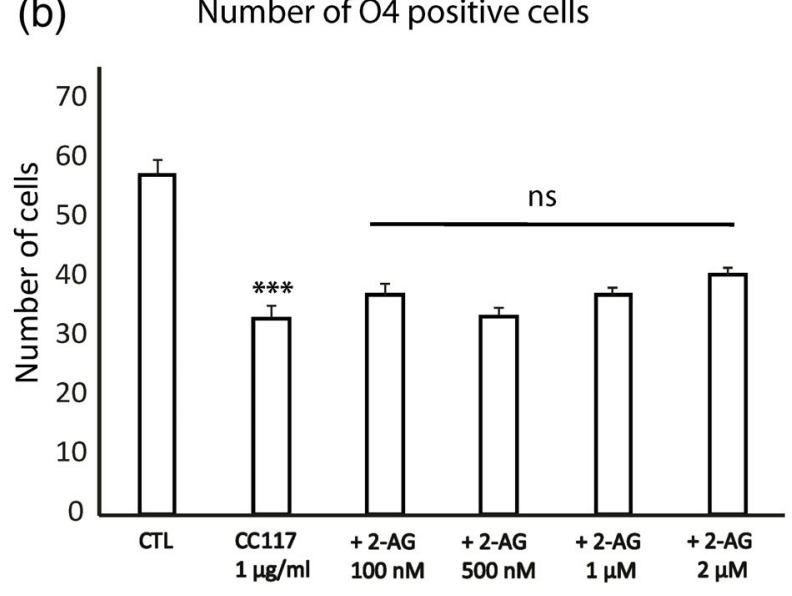

Number of $\mathrm{O} 4$ positive cells

(b)

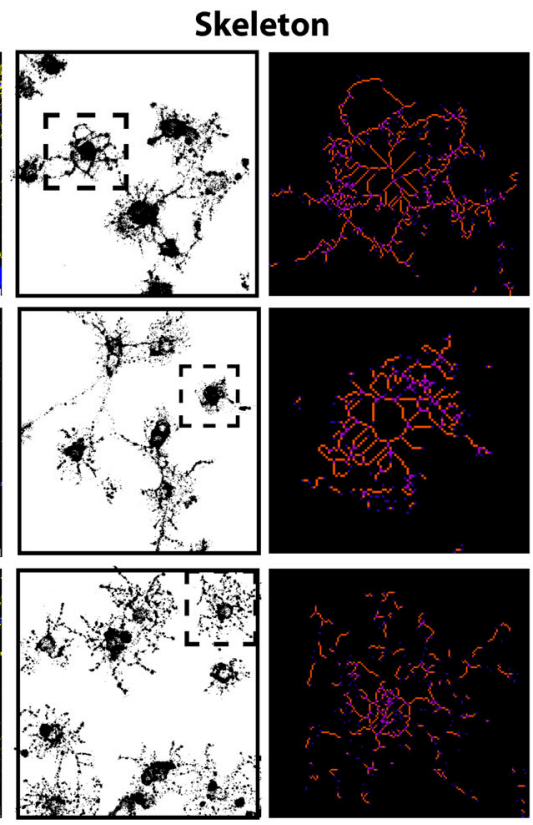

Complexity of

$\mathrm{O} 4$ positive cells

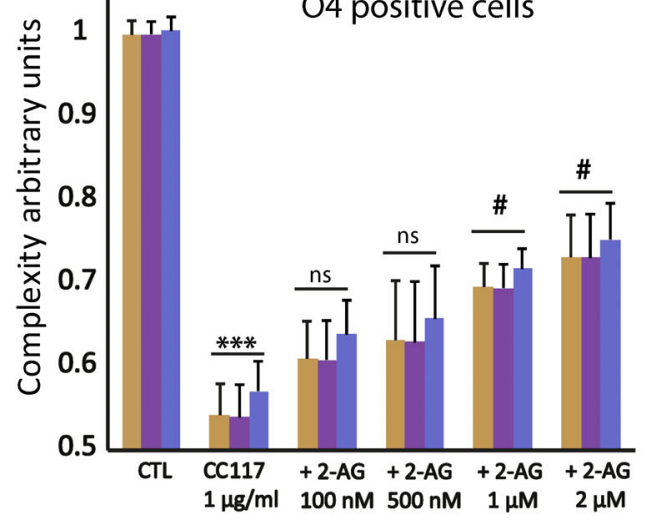

-Branches

- Juntions

-End-points

FIGURE 7 2-AG promotes the differentiation of $\mathrm{O} 4$ positive oligodendrocytes cultured on an inhibitory substrate. Rat oligodendrocytes cultured for $24 \mathrm{hr}$ on a synthetic CSPG matrix (\#CC117, $1 \mu \mathrm{g} / \mathrm{ml}$ ) and treated for $24 \mathrm{hr}$ with 2-AG at 100, 500, 1, and $2 \mu \mathrm{M}$. (a) Representative immunocytochemistry for $\mathrm{O} 4$ (yellow) and DAPI (blue), and their skeletons. (b) The number of $\mathrm{O} 4$ positive cells/field (c) Branches, junctions, and end-points obtained from the skeleton data. Scale bar: $50 \mu \mathrm{m}$. The data represent the mean \pm SEM: $* * * p<.001$ versus CTL; \#p <.05 versus CC117. ns, not significant. Nonparametric Kruskal-Wallis test (five independent experiments, two replicates per experiment). 2-AG,

2-arachidonoylglycerol; CSPGs, chondroitin sulfate proteoglycans

generated and the outgrowth of processes was analyzed after $24 \mathrm{hr}$ by immunocytochemistry for $\mathrm{O} 4$ staining (Figure 6a), while the morphological complexity of the OPCs was assessed by measuring their branches, junctions and end-points (Figure 6c). We found that OPCs plated onto a TGF- $\beta 1$ stimulated astrocyte matrix developed a less complex morphology than those plated onto a control matrix, suggesting a weaker differentiation. The matrix produced by 2-AG treated astrocytes induced more outgrowth of OPC processes, with more branches, junctions and end-points. No effect was observed on the initial cell adhesion under any experimental condition (Figure 6b).

\section{7 | 2-AG treatment promotes oligodendrocyte differentiation under inhibitory conditions}

To study whether 2-AG directly promotes the differentiation of OPCs plated onto an inhibitory ECM, rat OPCs were enriched from mixed glial cultures and they were seeded onto 24-well plates coated with a commercial mixture of CSPGs (\#CC117; $1 \mu \mathrm{g} / \mathrm{ml}$, mostly containing neurocan, phosphacan, versican, and aggrecan). These cells were then exposed to 2-AG for $24 \mathrm{hr}$ at concentrations of $100,500,1$, and $2 \mu \mathrm{M}$, and their morphological complexity was analyzed after staining for $\mathrm{O} 4$ (Figure 7a) and MBP (Figure 8a). Cell adhesion to the mixture of 
(a)

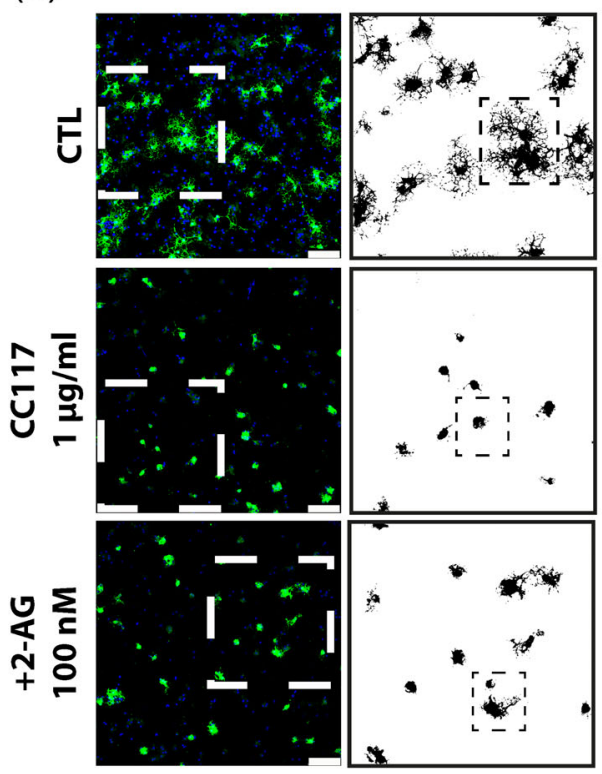

Skeleton

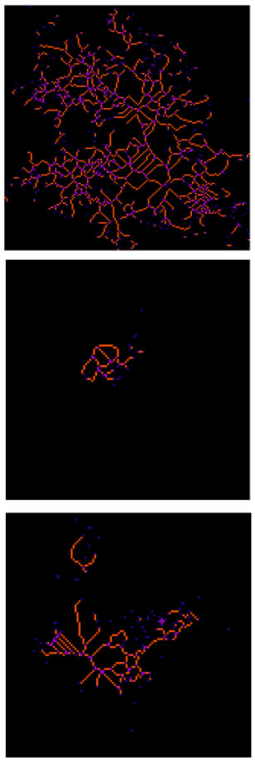

MBP/DAPI
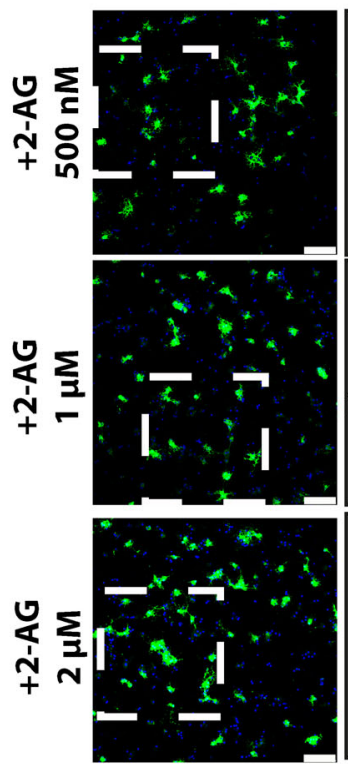

Skeleton

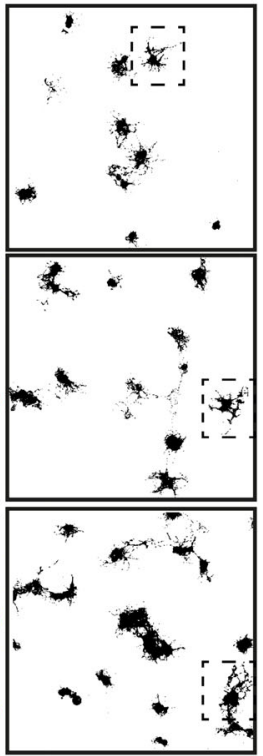

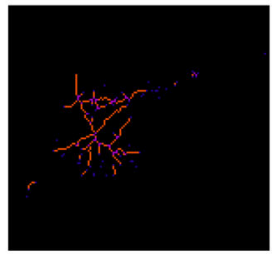

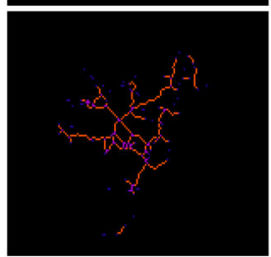

(b)

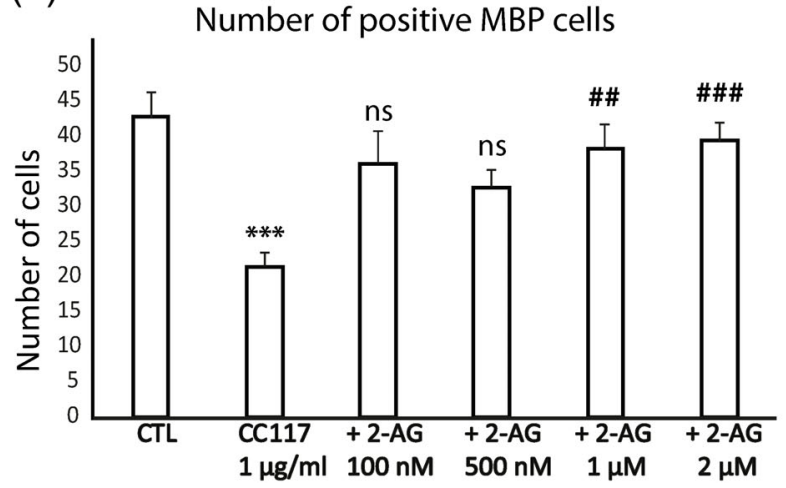

(c)

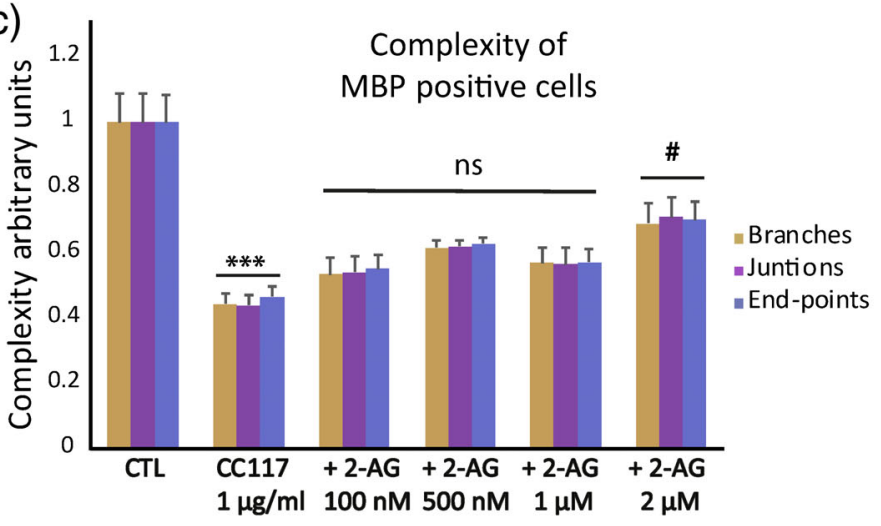

FIG URE 8 2-AG promotes the differentiation of MBP positive oligodendrocytes on an inhibitory substrate. Rat oligodendrocytes cultured for $24 \mathrm{hr}$ on a synthetic CSPGs matrix (\#CC117, $1 \mu \mathrm{g} / \mathrm{ml}$ ) and treated for $24 \mathrm{hr}$ with 2-AG at 100, 500, 1, and $2 \mu \mathrm{M}$. (a) Representative immunocytochemistry for MBP (green) and DAPI (blue), and their skeletons. (b) The number of MBP positive cells/field (c) Branches, junctions, and end-points obtained from the skeleton data. Scale bar: $100 \mu \mathrm{m}$. The data represent the mean \pm SEM: $* * * p<.001$ versus CTL; \# $p<.05$, \#\# $p<.01$, \#\#\# $p<.001$ versus CC117. ns, not significant. One-way ANOVA test followed by the Bonferroni and Tukey's post hoc tests were used for complexity analysis and non-parametric Kruskal-Wallis test for the number of cells analysis (three independent experiments, two replicates per experiment). 2-AG, 2-arachidonoylglycerol; CSPGs, chondroitin sulfate proteoglycans

CSPGs was worse (Figures $7 \mathrm{~b}$ and $8 \mathrm{~b}$ ) and this matrix significantly inhibited the outgrowth of oligodendrocytes, producing fewer arborizations (Figures 7a and 8a) and less complexity in terms of branches, junctions, and end-points (Figures 7c and 8c). By contrast, OPCs that were plated onto CSPGs and immediately exposed to 2-AG developed elaborated arborizations that reached a significant level in the case of 2-AG 1 and $2 \mu \mathrm{M}$ for 04 staining (Figure 7c; $p<.05$ vs. CC117). The staining with MBP also was affected by the treatment with 2-AG as we observed an increase in the morphological complexity of the cells that reached statistical significance with at $2 \mu \mathrm{M}$ dose (Figure 8c; $p<.05$ vs CC117). The endocannabinoid treatment did not modify the number of $\mathrm{O} 4$ positive cells adhere the inhibitory substrate (Figure $7 \mathrm{~b}$ ) but a significant increase in the number of MBP positive cells at doses of 1 and $2 \mu \mathrm{M}$ were observed (Figure 8b; $p<.01$ and $p<.001$ vs. CC117, respectively).

To study the effects of 2-AG on human oligodendrocyte outgrowth, we isolated primary human OPCs from surgically resected brain tissue obtained from patients with refractory epilepsy to treatments. These cells were seeded onto 24-well plates coated with the commercial CSPG mixture $(1 \mu \mathrm{g} / \mathrm{ml})$ and they were immediately treated for $24 \mathrm{hr}$ with 2-AG $(2 \mu \mathrm{M})$, staining the cells for O4 (Figure 9) to analyze their morphology using ImageJ. The adhesion of these cells to the commercial CSPG matrix was not significantly impaired, as evaluated by the number of $\mathrm{O} 4$ positive cells attached to the plate (Figure 9b). However, there was a significantly poorer outgrowth of processes, with fewer arborizations evident through $\mathrm{O} 4$ 
(a)
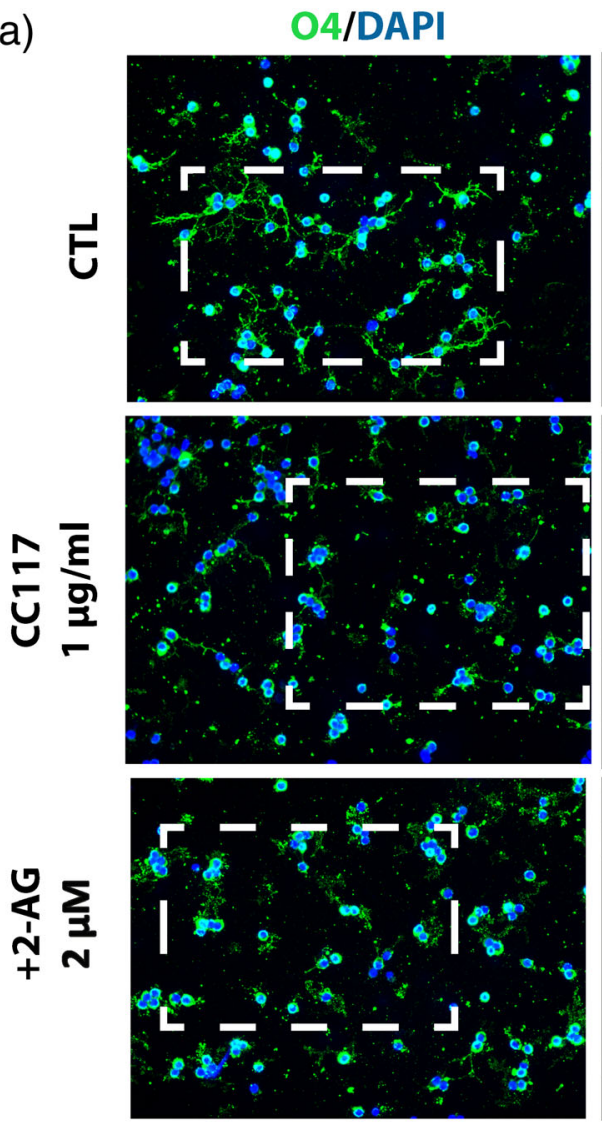

(b)

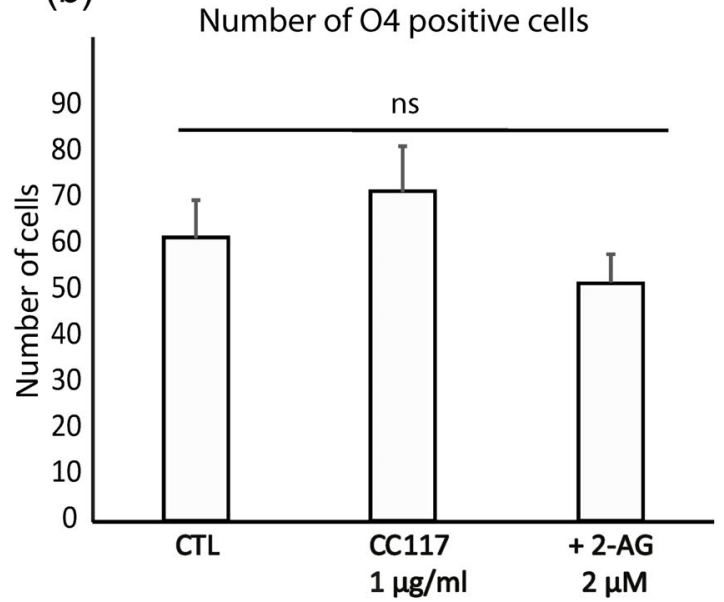

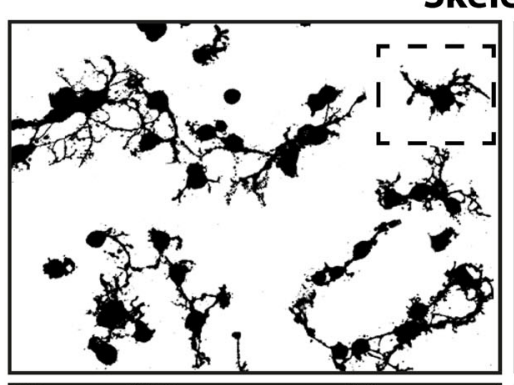

\section{Skeleton}
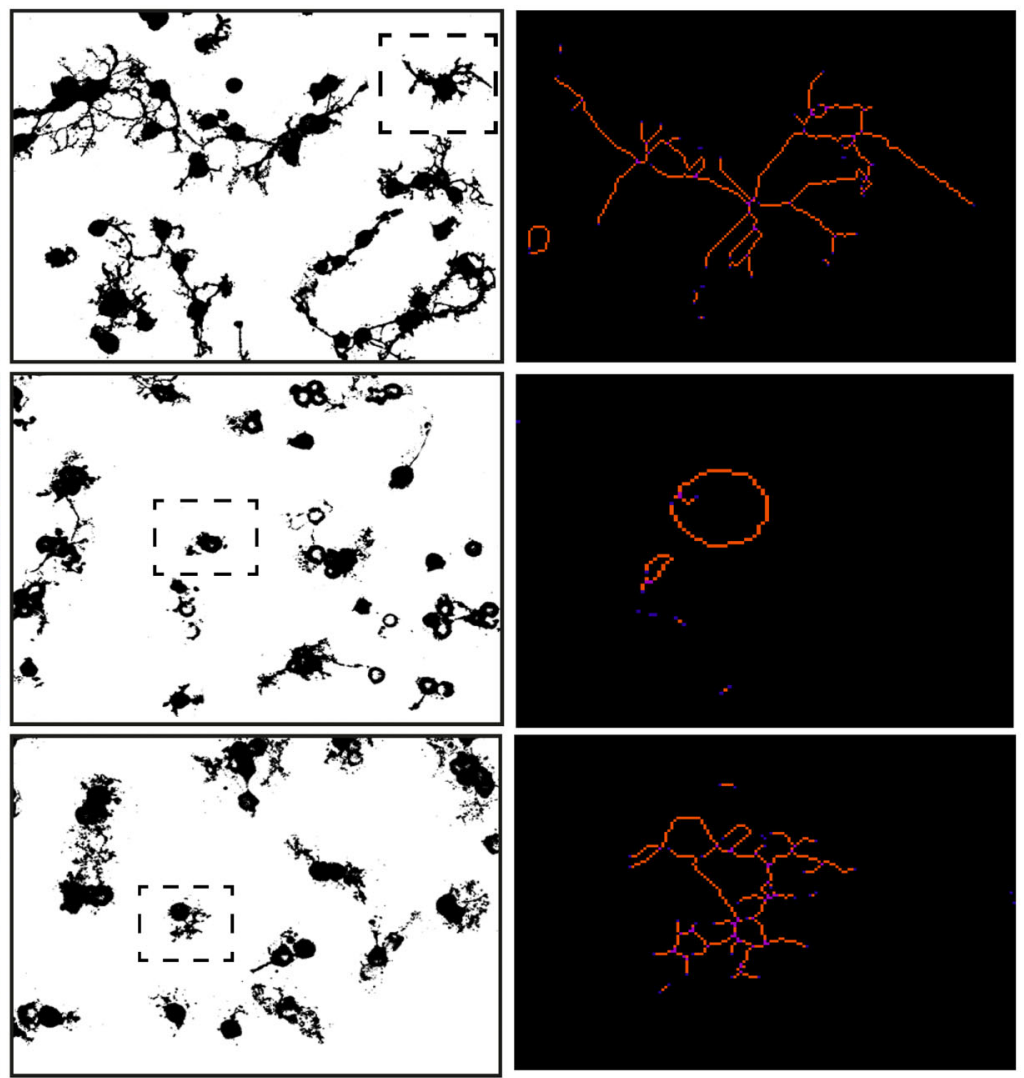

(c)

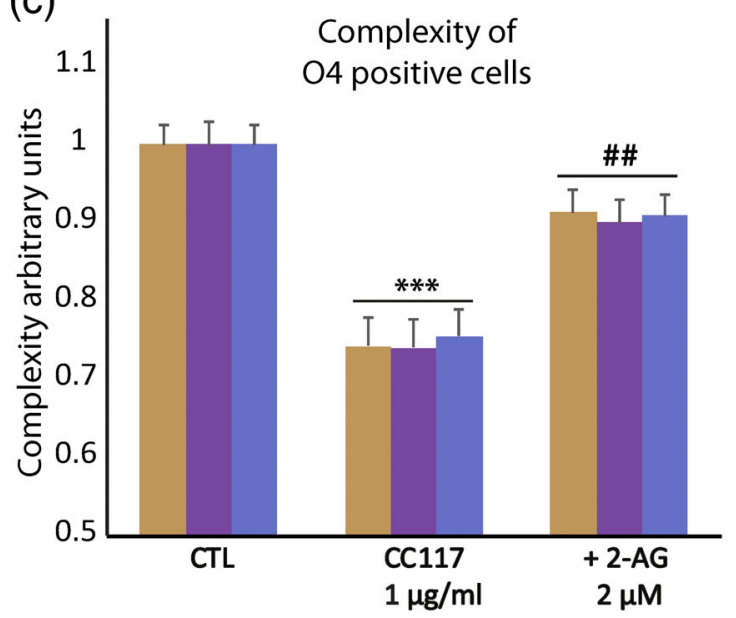

- Branches

- Juntions

- End-points

FIGURE 9 2-AG promotes the differentiation of human oligodendrocytes cultured on an inhibitory substrate. Human oligodendrocytes obtained from biopsies and cultured for $24 \mathrm{hr}$ on a synthetic CSPGs matrix (\#CC117, $1 \mu \mathrm{g} / \mathrm{ml}$ ) and treated with 2-AG (2 $\mu$ M). (a) Representative immunocytochemistry for O4 (green) and DAPI (blue), and their respective skeletons. (b) The number of O4 positive cells/field (c) Branches, junctions, and end-points obtained from the skeleton data. The data represent the mean \pm SEM: *** $p<.001$ versus CTL; \#\#p <.01 versus CC117. ns, not significant. One-way ANOVA test followed by the Bonferroni and Tukey's post hoc tests (representative experiment, five replicates per condition). 2-AG, 2-arachidonoylglycerol; CSPGs, chondroitin sulfate proteoglycans

immunocytochemistry (Figure 9a) and a reduced complexity when branches, junctions and end-points were analyzed (Figure 9c; $p<.001$ vs. CTL). By contrast, human OPCs plated on CSPGs and treated with 2-AG $(2 \mu \mathrm{M})$ displayed significantly more elaborated arborizations (Figure 9c; $p<.01$ vs. CC117), but again, there was no effect on their adhesion (Figure $9 \mathrm{~b}$ ).

\section{DISCUSSION}

In recent years, the interest in astrocytes as potential targets for neurotherapies has grown, particularly given their role as primary mediators of reactive gliosis and in maintaining immune homeostasis in the brain, along with microglia. Currently, therapies targeting the 
inflammatory component of MS have helped reduce the frequency of relapses, yet they are ineffective in halting disease progression. Clinical and experimental data suggest that such therapies do not enhance endogenous remyelination and regeneration sufficiently in the progressive phase of MS. Then, it is important to develop therapies that enhance reparative processes. CSPGs are molecules that may interfere with endogenous repair mechanisms, particularly as they accumulate in the glial scar. They are considered inhibitory molecules that impede remyelination and regeneration. In order to promote reparative mechanisms, combined therapies that neutralize the inhibitory environment around the demyelinated lesions and that enhance oligodendrocyte differentiation would favor the remyelination processes. In this study, we addressed whether the endocannabinoid 2-AG reduces the production of CSPGs by astrocytes in culture and whether the ECM generated by 2-AG-treated astrocytes is less inhibitory to oligodendrocyte differentiation. In addition, the effect of 2-AG on oligodendrocyte differentiation was assessed in the presence of a synthetic ECM enriched in CSPGs.

By secreting cytokines and chemokines that alter immune responses, astrocytes can potentiate inflammatory responses in situations of infection, trauma, ischemia, or neurodegenerative pathologies. Indeed, they are the main mediators of reactive gliosis, and they are responsible for CSPG synthesis and glial scar formation, a pathological feature of MS (Sofroniew \& Vinters, 2010; Wu \& Raine, 1992). The increase we found in neurocan and brevican by TGF- $\beta 1$-stimulated astrocytes is similar to that seen previously (Asher et al., 2000; Gris, Tighe, Levin, Sharma, \& Brown, 2007; Hamel et al., 2005; Jones, Margolis, \& Tuszynski, 2003; McKeon, Jurynec, \& Buck, 1999; Schachtrup et al., 2010; Sobel, 2001; Tang, Davies, \& Davies, 2003; Wang et al., 2008), evidence that this cytokine enhances the expression of a whole battery of enzymes responsible for CSPG production by astrocytes (Asher et al., 2000; Gris et al., 2007; Hamel et al., 2005; Smith \& Strunz, 2005; Wang et al., 2008) in agreement with the results of the present study. In addition, the enhanced neurocan by immunostaining and ELISAs have also been observed previously (Asher et al., 2000; Smith \& Strunz, 2005). Notably, TGF- $\beta 1$ induces a similar response in rat and human astrocytes, increasing CSPG production as evident in western blots and ELISAs, an effect seen previously by other groups (Keough et al., 2016).

TGF- $\beta 1-S M A D$ signaling is the canonical pathway involved in CSPGs production (Massague, Seoane, \& Wotton, 2005) and SMAD2 and SMAD3 knockdown reduce CSPG production by astrocytes (Susarla et al., 2011). Activation of this pathway was also evident here and following TGF- $\beta 1$ stimulation of astrocytes, there is an increment in SMAD2 and SMAD3 phosphorylation likely associated with enhanced neurocan and brevican synthesis.

Regarding the endocannabinoid system, we convincingly show that 2-AG diminished the production of CSPGs by rat and human astrocytes. We provide evidence that 2-AG reduces the expression of the enzymes involved in the synthesis of CSPGs, XT-1, and CS4T, and that 2-AG is capable to reduce the gene expression of brevican. Consequently, the effect of 2-AG seems to be independent of the activity of matrix metalloproteinases (MMPs) that would degrade CSPGs.
Although these enzymes could be acting at extracellular level degrading secreted CSPGs from astrocytes and we cannot discard completely the influence of MMPs activity on the effects of 2-AG at extracellular level, there is evidence showing that endocannabinoids inhibit hypoxia-induced MMP9 and MMP2 activities (Mukhopadhyay \& Tulis, 2007).

Interestingly, direct exposure of stimulated astrocytes to 2-AG dampens SMAD2 phosphorylation, in conjunction with reduced intracellular and extracellular levels of neurocan and brevican. In addition, we also observed a reduction in CSPG expression and extracellular release when TGF- $\beta 1$ stimulated human astrocytes were treated with 2-AG. The increase of 2-AG by the inhibition of MAGL and ABHD6 also reduces the intracellular expression of brevican and neurocan. The reduction in CSPG expression by MAGL inhibitors and by 2-AG in cultured astrocytes is consistent with our previous data obtained in vivo, whereby administration of the same MAGL inhibitor (UCM03025) reduced astrogliosis and CSPG accumulation in the spinal cord of a chronic progressive mouse model of MS (Feliu et al., 2017). Indeed, 2-AG and other MAGL inhibitors were previously shown to attenuate symptoms in the EAE model (Bernal-Chico et al., 2015; Hernández-Torres et al., 2014; Lourbopoulos et al., 2011). It is important to remark that in the present study MAGL is the hydrolysis enzyme that plays the main role in regulating the availability of 2-AG to reduce neurocan (in agreement with MAGL high expression in astrocytes), whereas $\mathrm{ABDH} 6$ may play a secondary role that in conjunction with MAGL is also crucial for the reduction of neurocan. Although inhibitors of the ABHD6 enzyme produced a similar reduction in intracellular and extracellular brevican despite hydrolyzing only $3 \%$ of the 2-AG, the therapeutic effect of ABHD6 inhibitors in vivo remains controversial. While there is evidence that inhibiting $\mathrm{ABDH} 6$ produces therapeutic effects in a CNS injury model (Tchantchou \& Zhang, 2013) or in the EAE model of MS (Wen, Ribeiro, Tanaka, \& Zhang, 2015), only modest effects were observed when ABHD6 was inhibited by KT182 in the cuprizone model of demyelination and in EAE (Manterola et al., 2018; Manterola et al., 2018). Our observations strongly suggest that 2-AG dampens the production of neurocan and brevican in TGF- $\beta 1$ stimulated astrocytes by modulating SMAD signaling.

2-AG is a full agonist of the CB1 and CB2 cannabinoid receptors (Sugiura, Kishimoto, Oka, \& Gokoh, 2006). Nevertheless, in our study only CB2R antagonism significantly blocked the effects of 2-AG on the phosphorylation of SMAD2 and on neurocan expression, suggesting that the reduction in neurocan induced by 2-AG is mediated through CB2R signaling. Although CB2R expression in astrocytes remains controversial, this receptor may be upregulated in astrocytes under inflammatory conditions. Indeed, CB2R expression has been described in $\mathrm{GFAP}^{+}$cells bordering white matter lesions in postmortem samples from MS patients (Benito et al., 2007), as well as in astrocytes in a model of SCl (García-Ovejero et al., 2009). In addition, CB2R activation modulates the production of different immune mediators in LPS-stimulated astrocytes treated with a selective endocannabinoid uptake inhibitor (Ortega-Gutiérrez, Molina-Holgado, \& Guaza, 2005), an effect that is also observed when human astrocytes 
are exposed to the synthetic cannabinoid WIN55,212-2 (Sheng et al., 2005). Indeed, CB2R activation in astrocytes, together with the activation of the $C B 1 R$ in neurons, is responsible for the beneficial actions of the potent synthetic cannabinoid, HU210, in a progressive model of MS (Docagne et al., 2007).

Several studies have focused on the modulation of the endocannabinoid system in order to regulate fibrotic responses in experimental models where there is an accumulation of collagen and ECM proteins. The CB1R has been identified as a pro-fibrotic receptor (Marquart et al., 2010; Yoshinaga et al., 2016), as corroborated in FAAH deficient mice in which the induction of fibrosis is dependent on the CB1R (Palumbo-Zerr et al., 2012). However, we did not find the CB1R to be involved in the 2-AG-induced reduction of CSPG production by astrocytes. By contrast, our data highlights the involvement of the $C B 2 R$ in the reduction of neurocan induced by 2-AG. The dampening of fibrotic processes by the CB2R has also been described in experimental models of skin fibrosis and tissue damage (Akhmetshina et al., 2009). More recent studies showed that an antagonist of the CB2R augments collagen synthesis in association with TGF- $\beta 1$ signaling and SMAD phosphorylation (Li et al., 2016). In addition, agonists of PPAR $\gamma$ and CB2Rs (julemic acid or the compound VCE-004.8, respectively), promote anti-fibrotic responses in experimental models of systemic sclerosis (Del Río et al., 2016; González et al., 2012). Moreover, activation of CB2Rs provokes anti-fibrotic responses through the inhibition of the TGF- $\beta 1 /$ SMAD pathway in a Nrf2 dependent manner (Li et al., 2016). All these studies are consistent with the results obtained here on the effects of 2-AG in reducing SMAD phosphorylation and neurocan production through $\mathrm{CB} 2 \mathrm{R}$ signaling.

The ECM generated by astrocytes in culture and a commercial ECM enriched in CSPGs both inhibit neurite outgrowth and oligodendrocyte differentiation (Cua et al., 2013; Karus et al., 2016; Keough et al., 2016; Lau et al., 2012; Pendleton et al., 2013; Siebert \& Osterhout, 2011). Accordingly, both ECMs reduce OPC maturation, although our astrocyte ECM inhibited oligodendrocyte differentiation less strongly than the commercial ECM, in contrast to an earlier study (Keough et al., 2016). The relative amounts of CSPGs probably differ between astrocyte and commercial ECMs, and moreover, the astrocyte-ECM is likely to have undefined factors that could help rescue the inhibitory effect of the CSPGs secreted by astrocytes. Indeed, such factors may explain some effects observed when oligodendrocytes are cultured on astrocyte-generated ECM. We also found that commercial CSPG-enriched ECM not only reduced human oligodendrocyte adhesion to the matrix but also their morphological complexity. Importantly, a significant reduction in the outgrowth of processes was also observed when human oligodendrocytes were cultured on this inhibitory ECM, although there was no reduction in the number of cells adhered to the matrix (Lau et al., 2012). Such, differences perhaps may be due to the distinct concentrations of commercial CSPGs used in the two studies (50 vs. $1 \mu \mathrm{g} / \mathrm{mL}$ in our study).

2-AG can promote oligodendrocyte differentiation indirectly through the generation of a less inhibitory ECM that modulates astrocyte responses, or by directly acting on oligodendrocytes to enhance their differentiation. Here, treating cultured astrocytes with 2-AG reduces the inhibitory ECM generated by astrocytes, enhancing oligodendrocyte outgrowth. Our results are consistent with astrocyte cultures producing an ECM rich in CSPGs that are inhibitory to neurite outgrowth, this inhibition being partly overcome by chondroitinase $A B C$ digestion and that of other agents (Cua et al., 2013). Interestingly, the ECM generated by astrocytes treated with Fluorosamine, a compound that dampens CSPG secretion, can also elevate oligodendrocyte outgrowth in culture (Keough et al., 2016). Encouragingly, 2-AG also enhances oligodendrocyte outgrowth even when cultured on the CSPG enriched commercial ECM, a beneficial effect that occurs when human oligodendrocytes are cultured under the same condition. The effects of 2-AG on the production of growth factors that could contribute to the generation of a more permissive environment for oligodendrocyte maturation in conjunction with reduced CSPG expression still needs to be clarified.

The promotion of oligodendrocyte maturation by 2-AG was reproduced by administering this endocannabinoid or by impeding its hydrolysis by inhibiting MAGL, inducing OPC proliferation and differentiation in vitro (Bernal-Chico et al., 2015; Gómez et al., 2010, 2011, 2015), and regulating their migration in culture (Sánchez-Rodríguez et al., 2018). These effects are mediated through CB1R and CB2R both present on OPCs and mature oligodendrocytes, being the Pi3kAkt signaling pathway involved in the promotion of oligodendrocytes differentiation by the endocannabinoid (Gómez et al., 2010, 2011). As such, following exposure to 2-AG or an increase in its endogenous tone, there is enhanced oligodendrocyte proliferation and differentiation that leads to successful remyelination in different models of demyelination in vivo: the TMEV-IDD model (Feliu et al., 2017), the EAE model of MS (Lourbopoulos et al., 2011) and the cuprizone model (Bernal-Chico et al., 2015). It is particularly interesting that both 2-AG and one inhibitor of the MAGL enzyme both reduce excitotoxic oligodendrocyte death (Bernal-Chico et al., 2015), an effect also attributed to other cannabinoids and under another toxic stimulus (Mecha et al., 2012; Ribeiro, Yu, Wen, Vana, \& Zhang, 2013).

Understanding the mechanisms that prevent remyelination in MS is critical to developing effective therapies that promote repair and remyelination in the progressive phase of MS. Astrocytes could be an interesting therapeutic target to bear in mind to reduce CSPG production and accumulation in demyelinated areas, also enhancing proregenerative responses. However, there is evidence that astrogliosis is not uniformly inhibitory to repair, then, our knowledge of the role of glial scar in tissue remodeling required intense research to untangle the complex interactions between neurons, axons, and glial cells.

Actually, 2-AG could act as a multi-target agent, not only as an immunomodulatory and neuroprotective lipid but also, targeting astrocytes to reduce their CSPG accumulation with beneficial effects on oligodendrocytes differentiation. The findings reported here suggest promising avenues of research and potential treatments for demyelinating pathologies.

\section{ACKNOWLEDGMENTS}

This work was supported by grants to CG from the Ministry of the Economy and Competition (MINECO: SAF2013-42784-R; 
SAF2016-76449-R) and from the Red Española de Esclerosis Múltiple (REEM) RD16/0015/0021. None of the funding bodies played any role in the study design, data collection, and analysis, the decision to publish, or the preparation of the manuscript. AF is a postdoctoral fellow supported by the MINECO (BES-2014-068459).

\section{CONFLICT OF INTEREST}

The authors have no competing financial interests to declare.

\section{DATA AVAILABILITY STATEMENT}

The data of this article are available if required

\section{ORCID}

V. Wee Yong (iD https://orcid.org/0000-0002-2600-3563 Carmen Guaza (D) https://orcid.org/0000-0003-3240-9807

\section{REFERENCES}

Akhmetshina, A., Dees, C., Busch, N., Beer, J., Sarter, K., Zwerina, J., ... Distler, J. H. (2009). The cannabinoid receptor CB2 exerts antifibrotic effects in experimental dermal fibrosis. Arthritis and Rheumatism, 60(4), 1129-1136. https://doi.org/10.1002/art.24395

Alonso, G., \& Privat, A. (1993). Reactive astrocytes involved in the formation of lesional scars differ in the mediobasal hypothalamus and in other forebrain regions. Journal of Neuroscience Research, 34(5), 523-538. https://doi.org/10.1002/jnr.490340505

Asher, R. A., Morgenstern, D. A., Fidler, P. S., Adcock, K. H., Oohira, A., Braistead, J. E., ... Fawcett, J. W. (2000). Neurocan is upregulated in injured brain and in cytokine-treated astrocytes. The Journal of Neuroscience, 20(7), 2427-2438. https://doi.org/10.1523/JNEUROSCI.2007-02427.2000

Back, S. A., Tuohy, T. M., Chen, H., Wallingford, N., Craig, A., Struve, J., ... Sherman, L. S. (2005). Hyaluronan accumulates in demyelinated lesions and inhibits oligodendrocyte progenitor maturation. Nature Medicine, 11, 966-972. https://doi.org/10.1038/nm1279

Bartus, K., James, N. D., Didangelos, A., Bosch, K. D., Verhaagen, J., YanezMunoz, R. J., ... Bradbury, E. J. (2014). Large-scale chondroitin sulfate proteoglycan digestion with chondroitinase gene therapy leads to reduced pathology and modulates macrophage phenotype following spinal cord contusion injury. The Journal of Neuroscience, 34(14), 4822-4836. https://doi.org/10.1523/JNEUROSCI.4369-13.2014

Benito, C., Romero, J. P., Tolón, R. M., Clemente, D., Docagne, F., Hillard, C. J., ... Romero, J. (2007). Cannabinoid CB1 and CB2 receptors and fatty acid amide hydrolase are specific markers of plaque cell subtypes in human multiple sclerosis. The Journal of Neuroscience, 27(9), 2396-2402. https://doi.org/10.1523/JNEUROSCI.4814-06.2007

Bernal-Chico, A., Canedo, M., Manterola, A., Victoria Sánchez-Gómez, M., Pérez-Samartín, A., Rodríguez-Puertas, R., ... Mato, S. (2015). Blockade of monoacylglycerol lipase inhibits oligodendrocyte excitotoxicity and prevents demyelination in vivo. GLIA, 63, 163-176. https://doi.org/10. 1002/glia.22742

Carulli, D., Rhodes, K. E., Brown, D. J., Bonnert, T. P., Pollack, S. J., Oliver, K., ... Fawcett, J. W. (2006). Composition of perineuronal nets in the adult rat cerebellum and the cellular origin of their components. The Journal of Comparative Neurology, 494, 559-577. https://doi.org/ $10.1002 /$ cne. 20822

Chang, A., Staugaitis, S. M., Dutta, R., Batt, C. E., Easley, K. E., Chomyk, A. M., ... Trapp, B. D. (2012). Cortical remyelination: A new target for repair therapies in multiple sclerosis. Annals of Neurology, 72, 918-926. https://doi.org/10.1002/ana.23693

Chang, A., Tourtellotte, W. W., Rudick, R., \& Trapp, B. D. (2002). Premyelinating oligodendrocytes in chronic lesions of multiple sclerosis. The New England Journal of Medicine, 346, 165-173. https:// doi.org/10.1056/NEJMoa010994

Compston, A., \& Coles, A. (2008). Multiple sclerosis. Lancet, 372, 1502-1517. https://doi.org/10.1016/S0140-6736(08)61620-7

Cua, R. C., Lau, L. W., Keough, M. B., Midha, R., Apte, S. S., \& Yong, V. W. (2013). Overcoming neurite-inhibitory chondroitin sulfate proteoglycans in the astrocyte matrix. GLIA, 61(6), 972-984. https://doi.org/10. 1002/glia.22489

Del Río, C., Navarrete, C., Collado, J. A., Bellido, M. L., Gómez-Canas, M. Pazos, M. R., ... Muñoz, E. (2016). The cannabinoid quinol VCE-004.8 alleviates bleomycin-induced scleroderma and exerts potent antifibrotic effects through peroxisome proliferator-activated receptor-gamma and CB2 pathways. Scientific Reports, 6, 21703. https://doi.org/10.1038/srep21703

Docagne, F., Muneton, V., Clemente, D., Ali, C., Loría, F., Correa, F., ... Guaza, C. (2007). Excitotoxicity in a chronic model of multiple sclerosis: Neuroprotective effects of cannabinoids through CB1 and CB2 receptor activation. Molecular and Cellular Neurosciences, 34(4), 551-561. https://doi.org/10.1016/j.mcn.2006.12.005

Dyck, S., Kataria, H., Akbari-Kelachayeh, K., Silver, J., \& KarimiAbdolrezaee, S. (2019). LAR and PTPo receptors are negative regulators of oligodendrogenesis and oligodendrocyte integrity in spinal cord injury. GLIA, 67, 125-145. https://doi.org/10.1002/glia.23533

Dyck, S. M., Alizadeh, A., Santhosh, K. T., Proulx, E. H., Wu, C. L., \& KarimiAbdolrezaee, S. (2015). Chondroitin sulfate proteoglycans negatively modulate spinal cord neural precursor cells by signaling through LAR and RPTP sigma and modulation of the rho/ROCK pathway. Stem Cells, 33(8), 2550-2563. https://doi.org/10.1002/stem.1979

Fawcett, J. W., \& Asher, R. A. (1999). The glial scar and central nervous system repair. Brain Research Bulletin, 49(6), 377-391. https://doi.org/ 10.1016/s0361-9230(99)00072-6

Feliu, A., Bonilla Del Río, I., Carrillo-Salinas, F. J., Hernández-Torres, G., Mestre, L., Puente, N., ... Guaza, C. (2017). 2-Arachidonoylglycerol reduces proteoglycans and enhances Remyelination in a progressive model of demyelination. The Journal of Neuroscience, 37(35), 8385-8398. https://doi.org/10.1523/JNEUROSCI.2900-16.2017

Fernández-Ruiz, J., García, C., Sagredo, O., Gómez-Ruiz, M., \& de Lago, E. (2010). The endocannabinoid system as a target for the treatment of neuronal damage. Expert Opinion on Therapeutic Targets, 14, 387-404. https://doi.org/10.1517/14728221003709792

Franklin, R. J. (2002). Why does remyelination fail in multiple sclerosis? Nature Reviews. Neuroscience, 3, 705-714. https://doi.org/10.1038/ nrn917

Frischer, J. M., Weigand, S. D., Guo, Y., Kale, N., Parisi, J. E., Pirko, I., .. Lucchinetti, C. F. (2015). Clinical and pathological insights into the dynamic nature of the white matter multiple sclerosis plaque. Annals of Neurology, 78, 710-721. https://doi.org/10.1002/ana.24497

Galtrey, C. M., \& Fawcett, J. W. (2007). The role of chondroitin sulfate proteoglycans in regeneration and plasticity in the central nervous system. Brain Research Reviews, 54, 1-18.

García-Ovejero, D., Arévalo-Martín, A., Petrosino, S., Docagne, F., Hagen, C., Bisogno, T., ... Molina-Holgado, E. (2009). The endocannabinoid system is modulated in response to spinal cord injury in rats. Neurobiology of Disease, 33(1), 57-71. https://doi.org/10.1016/j. nbd.2008.09.015

Giuliani, F., Goodyer, C. G., Antel, J. P., \& Yong, V. W. (2003). Vulnerability of human neurons to T cell-mediated cytotoxicity. Journal of Immunology, 171, 368-379. https://doi.org/10.4049/jimmunol.171.1.368

Goldschmidt, T., Antel, J., Konig, F. B., Bruck, W., \& Kuhlmann, T. (2009). Remyelination capacity of the MS brain decreases with disease chronicity. Neurology, 72, 1914-1921. https://doi.org/10.1212/WNL. Ob013e3181a8260a

Gómez, O., Arévalo-Martin, A., García-Ovejero, D., Ortega-Gutierrez, S., Cisneros, J. A., Almazan, G., ... Molina-Holgado, E. (2010). The constitutive production of 2-arachidonoylglycerol participates in 
oligodendrocyte differentiation. GLIA, 58, 1913-1927. https://doi. org/10.1002/glia.21061

Gómez, O., Sánchez-Rodríguez, M. A., Le, M., Sánchez-Caro, C., MolinaHolgado, F., \& Molina-Holgado, E. (2011). Cannabinoid receptor agonists modulate oligodendrocyte differentiation by activating PI3K/Akt and the mammalian target of rapamycin (mTOR) pathways. British Journal of Pharmacology, 163, 1520-1532. https://doi.org/10.1111/j. 1476-5381.2011.01414x

Gómez, O., Sánchez-Rodríguez, M. A., Ortega-Gutiérrez, S., VázquezVilla, H., Guaza, C., Molina-Holgado, F., \& Molina-Holgado, E. (2015). A basal tone of 2-arachidonoylglycerol contributes to early oligodendrocyte progenitor proliferation by activating phosphatidylinositol 3-kinase (PI3K)/AKT and the mammalian target of rapamycin (mTOR) pathways. Journal of Neuroimmune Pharmacology, 10(2), 309-317. https://doi.org/10.1007/s11481-015-9609-x

González, E. G., Selvi, E., Balistreri, E., Akhmetshina, A., Palumbo, K., Lorenzini, S., ... Distler, J. H. (2012). Synthetic cannabinoid ajulemic acid exerts potent antifibrotic effects in experimental models of systemic sclerosis. Annals of the Rheumatic Diseases, 71(9), 1545-1551. https://doi.org/10.1136/annrheumdis-2011-200314

Gris, P., Tighe, A., Levin, D., Sharma, R., \& Brown, A. (2007). Transcriptional regulation of scar gene expression in primary astrocytes. GLIA, 55(11), 1145-1155. https://doi.org/10.1002/glia.20537

Hamel, M. G., Mayer, J., \& Gottschall, P. E. (2005). Altered production and proteolytic processing of brevican by transforming growth factor beta in cultured astrocytes. Journal of Neurochemistry, 93(6), 1533-1541. https://doi.org/10.1111/j.1471-4159.2005.03144.x

Hernández-Torres, G., Cipriano, M., Hedén, E., Bjorklund, E., Canales, A., Zian, D., ... López-Rodríguez, M. L. (2014). A reversible and selective inhibitor of monoacylglycerol lipase ameliorates multiple sclerosis. Angewandte Chemie (International Ed. in English), 53, 13765-13770. https://doi.org/10.1002/anie.201407807

Jones, L. L., Margolis, R. U., \& Tuszynski, M. H. (2003). The chondroitin sulfate proteoglycans neurocan, brevican, phosphacan, and versican are differentially regulated following spinal cord injury. Experimental Neurology, 182(2), 399-411. https://doi.org/10.1016/S0014-4886(03) 00087-6

Karus, M. A., Ulc, M., Ehrlich, T., Czopka, E., Hennen, J., Fischer, M., ... Faissner, A. (2016). Regulation of oligodendrocyte precursor maintenance by chondroitin sulphate glycosaminoglycans. GLIA, 64(2), 270-286. https://doi.org/10.1002/glia.22928

Keough, M. B., Rogers, J. A., Zhang, P., Jensen, S. K., Stephenson, E. L., Chen, T., ... Yong, V. W. (2016). An inhibitor of chondroitin sulfate proteoglycan synthesis promotes central nervous system remyelination. Nature Communications, 7, 11312. https://doi.org/10.1038/ ncomms11312

Lang, B. T., Cregg, J. M., DePaul, M. A., Tran, A. P., Xu, K., Dyck, S. M., ... Silver, J. (2015). Modulation of the proteoglycan receptor PTP sigma promotes recovery after spinal cord injury. Nature, 518(7539), 404-408. https://doi.org/10.1038/nature13974

Lassmann, H. (2017). Targets of therapy in progressive MS. Multiple Sclerosis, 23(12), 1593-1599. https://doi.org/10.1177/1352458517729455

Lassmann, H., Bruck, W., \& Lucchinetti, C. (2001). Heterogeneity of multiple sclerosis pathogenesis: Implications for diagnosis and therapy. Trends in Molecular Medicine, 7, 115-121. https://doi.org/10.1016/ S1471-4914(00)01909-2

Lau, L. W., Keough, M. B., Haylock-Jacobs, S., Cua, R., Doring, A., Sloka, S., ... Yong, V. W. (2012). Chondroitin sulfate proteoglycans in demyelinated lesions impair demyelination. Annals of Neurology, 72, 419-432. https://doi.org/10.1002/ana.23599

Li, S., Wang, L., Liu, M., Jiang, S., Zhang, M., Tian, Z., ... Guan, D. (2016). Cannabinoid $C_{2}$ receptors are involved in the regulation of fibrogenesis during skin wound repair in mice. Molecular Medicine Reports, 13, 3441-3450. https://doi.org/10.3892/mmr.2016.4961
Li, X., Han, D., Tian, Z., Gao, B., Fan, M., Li, C., ... Cao, F. (2016). Activation of cannabinoid receptor type II by AM1241 ameliorates myocardial fibrosis via Nrf2-mediated inhibition of infarction mice. Cellular Physiology and Biochemistry, 39, 1521-1536. https://doi.org/10.1159/ 000447855

Loría, F., Petrosino, S., Hernangómez, M., Mestre, L., Spagnolo, A., Correa, F., ... Guaza, C. (2010). An endocannabinoid tone limits excitotoxicity in vitro and in a model of multiple sclerosis. Neurobiology of Disease, 37, 166-176. https://doi.org/10.1016/j.nbd.2009.09.020

Lourbopoulos, A., Grigoriadis, N., Lagoudaki, R., Touloumi, O., Polyzoidou, E., Mavromatis, I., ... Simeonidou, C. (2011). Administration of 2-arachidonoylglycerol ameliorates both acute and chronic experimental autoimmune encephalomyelitis. Brain Research, 1390, 126-141. https://doi.org/10.1016/j.brainres.2011.03.020

Manterola, A., Bernal-Chico, A., Cipriani, R., Canedo-Antelo, M., MorenoGarcía, Á., Martín-Fontecha, M., ... Mato, S. (2018). Deregulation of the endocannabinoid system and therapeutic potential of ABHD6 blockade in the cuprizone model of demyelination. Biochemical Pharmacology, 157, 189-201. https://doi.org/10.1016/j.bcp.2018.07.042

Manterola, A., Bernal-Chico, A., Cipriani, R., Ruiz, A., Pérez-Samartín, A., Moreno-Rodríguez, M., ... Mato, S. (2018). Re-examining the potential of targeting ABHD6 in multiple sclerosis: Efficacy of systemic and peripherally restricted inhibitors in experimental autoimmune encephalomyelitis. Neuropharmacology, 141, 181-191. https://doi.org/10. 1016/j.neuropharm.2018.08.038

Marquart, S., Zerr, P., Akhmetshina, A., Palumbo, K., Reich, N., Tomcik, M., ... Distler, J. H. (2010). Inactivation of the cannabinoid receptor CB1 prevents leukocyte infiltration and experimental fibrosis. Arthritis and Rheumatism, 62(11), 3467-3476. https://doi.org/10.1002/art.27642

Massague, J., Seoane, J., \& Wotton, D. (2005). Smad transcription factors. Genes \& Development, 19(23), 2783-2810. https://doi.org/10.1101/ gad.1350705

McKeon, R. J., Jurynec, M. J., \& Buck, C. R. (1999). The chondroitin sulfate proteoglycans neurocan and phosphacan are expressed by reactive astrocytes in the chronic CNS glial scar. The Journal of Neuroscience, 19(24), 10778-10788.

Mecha, M., Feliú, A., Carrillo-Salinas, F. J., Rueda-Zubiaurre, A., OrtegaGutiérrez, S., de Sola, R. G., \& Guaza, C. (2015). Endocannabinoids drive the acquisition of an alternative phenotype in microglia. Brain, Behavior, and Immunity, 49, 233-245. https://doi.org/10.1016/j.bbi. 2015.06.002

Mecha, M., Iñigo, P. M., Mestre, L., Hernangómez, M., Borrel, J., \& Guaza, C. (2011). An easy and fast way to obtain a high number of glial cells from rat cerebral tissue: A beginners approach. Protocol Exchange. https://doi.org/10.1038/protex.2011.218

Mecha, M., Torrao, A. S., Mestre, L., Carrillo-Salinas, F. J., Mechoulam, R., \& Guaza, C. (2012). Cannabidiol protects oligodendrocyte progenitor cells from inflammation-induced apoptosis by attenuating endoplasmic reticulum stress. Cell Death \& Disease, 3, e331. https://doi.org/10.1038/cddis.2012.71

Mecha, M., Yanguas-Casás, N., Feliú, A., Mestre, L., Carrillo-Salinas, F., Azcoitia, I., ... Guaza, C. (2019). The endocannabinoid 2-AG enhances spontaneous remyelination by targeting microglia. Brain, Behavior, and Immunity, 77, 110-126. https://doi.org/10.1016/j.bbi.2018.12.013

Molina-Holgado, E., Vela, J. M., Arévalo-Martín, A., Almazán, G., MolinaHolgado, F., Borrell, J., \& Guaza, C. (2002). Cannabinoids promote oligodendrocyte progenitor survival: Involvement of cannabinoid receptors and phosphatidylinositol-3 kinase/Akt signaling. The Journal of Neuroscience, 22, 9742-9753. https://doi.org/10.1523/JNEUROSCl. 22-22-09742.2002

Morrison, H. W., \& Filosa, J. A. (2013). A quantitative spatiotemporal analysis of microglia morphology during ischemic stroke and reperfusion. Journal of Neuroinflammation, 10, 4. https://doi.org/10.1186/17422094-10-4 
Mukhopadhyay, S., \& Tulis, D. A. (2007). Endocannabinoid regulation of matrix metalloproteinases: Implications in ischemic stroke. Cardiovascular \& Hematological Agents in Medicinal Chemistry, 5(4), 311-318. https://doi.org/10.2174/18752507782109917

Nuttall, R. K., Silva, C., Bar-Or, A., Patel, K., Edwards, D. R., \& Yong, V. W. (2007). Metalloproteinases (MMPs and ADAMs) are enriched in microglia compared to leukocytes and they link microglia activation with cytokine levels. GLIA, 55, 516-526.

Ortega-Gutiérrez, S., Molina-Holgado, E., \& Guaza, C. (2005). Effect of anandamide uptake inhibition in the production of nitric oxide and in the release of cytokines in astrocyte cultures. GLIA, 52(2), 163-168. https://doi.org/10.1002/glia.20229

Palumbo-Zerr, K., Horn, A., Distler, A., Zerr, P., Dees, C., Beyer, C., ... Distler, J. H. (2012). Inactivation of fatty acid amide hydrolase exacerbates experimental fibrosis by enhanced endocannabinoid-mediated activation of CB1. Annals of the Rheumatic Diseases, 71(12), 2051-2054. https://doi.org/10.1136/annrheumdis-2012-201823

Pendleton, J. C., Shamblott, M. J., Gary, D. S., Belegu, V., Hurtado, A., Malone, M. L., \& McDonald, J. W. (2013). Chondroitin sulfate proteoglycans inhibit oligodendrocyte myelination through PTP. Experimental Neurology, 247, 113-121. https://doi.org/10.1016/j.expneurol.2013. 04.003

Pryce, G., Ahmed, Z., Hankey, D. J., Jackson, S. J., Croxford, J. L., Pocock, J. M., ... Baker, D. (2003). Cannabinoids inhibit neurodegeneration in models of multiple sclerosis. Brain, 126, 2191-2202. https://doi.org/10.1093/brain/awg224

Reier, P. J., \& Houle, J. D. (1988). The glial scar: Its bearing on axonal elongation and transplantation approaches to CNS repair. Advances in Neurology, 47, 87-138.

Ribeiro, R., Yu, F., Wen, J., Vana, A., \& Zhang, Y. (2013). Therapeutic potential of a novel cannabinoid agent CB52 in the mouse model of experimental autoimmune encephalomyelitis. Neuroscience, 254, 427-442. https://doi.org/10.1016/j.neuroscience.2013.09.005

Rolls, A., Shechter, R., London, A., Segev, Y., Jacob-Hirsch, J., Amariglio, N., ... Schwartz, M. (2008). Two faces of chondroitin sulfate proteoglycan in spinal cord repair: A role in microglia/macrophage activation. PLoS Medicine, 5(8), e171. https://doi.org/10.1371/journal.pmed.0050171

Sánchez-Rodríguez, M. A., Gómez, O., Esteban, P. F., García-Ovejero, D., \& Molina-Holgado, E. (2018). The endocannabinoid 2-arachidonoylglycerol regulates oligodendrocyte progenitor cell migration. Biochemical Pharmacology, 157, 180-188. https://doi.org/ 10.1016/j.bcp.2018.09.006

Schachtrup, C., Ryu, J. K., Helmrick, M. J., Vagena, E., Galanakis, D. K., Degen, J. L., ... Akassoglou, K. (2010). Fibrinogen triggers astrocyte scar formation by promoting the availability of active TGF- $\beta$ after vascular damage. The Journal of Neuroscience, 30(17), 5843-5854. https://doi.org/10.1523/JNEUROSCI.0137-10.2010

Sheng, W. S., Hu, S., Min, X., Cabral, G. A., Lokensgard, J. R., \& Peterson, P. K. (2005). Synthetic cannabinoid WIN55,212-2 inhibits generation of inflammatory mediators by IL-1beta-stimulated human astrocytes. GLIA, 49(2), 211-219. https://doi.org/10.1002/glia.20108

Siebert, J. R., \& Osterhout, D. J. (2011). The inhibitory effects of chondroitin sulfate proteoglycans on oligodendrocytes. Journal of Neurochemistry, 119, 176-188. https://doi.org/10.1111/j.1471-4159.2011. 07370.x

Silver, J., \& Miller, J. H. (2004). Regeneration beyond the glial scar. Nature Reviews. Neuroscience, 5(2), 146-156. https://doi.org/10.1038/ nrn1326

Smith, G. M., \& Strunz, C. (2005). Growth factor and cytokine regulation of chondroitin sulfate proteoglycans by astrocytes. GLIA, 52(3), 209-218. https://doi.org/10.1002/glia.20236
Sobel, R. A. (2001). The extracellular matrix in multiple sclerosis: An update. Brazilian Journal of Medical and Biological Research, 34(5), 603-609. https://doi.org/10.1590/S0100-879X2001000500007

Sobel, R. A., \& Ahmed, A. S. (2001). White matter extracellular matrix chondroitin sulfate/dermatan sulfate proteoglycans in multiple sclerosis. Journal of Neuropathology and Experimental Neurology, 60, 1198-1207.

Sofroniew, M. V., \& Vinters, H. V. (2010). Astrocytes: Biology and pathology. Acta Neuropathologica, 119(1), 7-35. https://doi.org/10.1007/ s00401-009-0619-8

Sugiura, T., Kishimoto, S., Oka, S., \& Gokoh, M. (2006). Biochemistry, pharmacology and physiology of 2-arachidonoylglycerol, an endogenous cannabinoid receptor ligand. Progress in Lipid Research, 45(5), 405-446. https://doi.org/10.1016/j.plipres.2006.03.003

Susarla, B. T., Laing, E. D., Yu, P., Katagiri, Y., Geller, H. M., \& Symes, A. J. (2011). Smad proteins differentially regulate transforming growth factor-beta-mediated induction of chondroitin sulfate proteoglycans. Journal of Neurochemistry, 119(4), 868-878. https://doi.org/10.1111/j. 1471-4159.2011.07470.x

Tang, X., Davies, J. E., \& Davies, S. J. (2003). Changes in distribution, cell associations, and protein expression levels of NG2, neurocan, phosphacan, brevican, versican $\mathrm{V} 2$, and tenascin-C during acute to chronic maturation of spinal cord scar tissue. Journal of Neuroscience Research, 71(3), 427-444. https://doi.org/10.1002/jnr.10523

Tchantchou, F., \& Zhang, Y. (2013). Selective inhibition of alpha/betahydrolase domain 6 attenuates neurodegeneration, alleviates blood brain barrier breakdown, and improves functional recovery in a mouse model of traumatic brain injury. Journal of Neurotrauma, 30(7), 565-579. https://doi.org/10.1089/neu.2012.2647

Wang, H., Katagiri, Y., McCann, T. E., Unsworth, E., Goldsmith, P., Yu, Z. X., ... Geller, H. M. (2008). Chondroitin-4-sulfation negatively regulates axonal guidance and growth. Journal of Cell Science, 121(Pt 18), 3083-3091. https://doi.org/10.1242/jcs.032649

Wen, J., Ribeiro, R., Tanaka, M., \& Zhang, Y. (2015). Activation of CB2 receptor is required for the therapeutic effect of ABHD6 inhibition in experimental autoimmune encephalomyelitis. Neuropharmacology, 99, 196-209. https://doi.org/10.1016/j.neuropharm.2015.07.010

Wu, E., \& Raine, C. S. (1992). Multiple sclerosis. Interactions between oligodendrocytes and hypertrophic astrocytes and their occurrence in other, nondemyelinating conditions. Laboratory Investigation, 67(1), 88-99.

Yoshinaga, T., Uwabe, K., Naito, S., Higashino, K., Nakano, T., Numata, Y., \& Kihara, A. (2016). AM251 suppresses epithelialMesenchymal transition of renal tubular epithelial cells. PLOS ONE, 11 (12), e0167848. https://doi.org/10.1371/journal.pone.0167848

Yu, P., Wang, H., Katagiri, Y., \& Geller, H. M. (2012). An in vitro model of reactive astrogliosis and its effect on neuronal growth. Methods in Molecular Biology, 814, 327-340. https://doi.org/10.1007/978-161779-452-0_21

How to cite this article: Feliu A, Mestre L, Carrillo-Salinas FJ, Yong VW, Mecha M, Guaza C. 2-arachidonoylglycerol reduces chondroitin sulphate proteoglycan production by astrocytes and enhances oligodendrocyte differentiation under inhibitory conditions. Glia. 2019;1-19. https://doi.org/10.1002/glia. 23775 